Supporting Information

\title{
Sensitive Oligodeoxynucleotide Synthesis Using Dim and Dmoc as Protecting Groups
}

Shahien Shahsavari, Dhananjani N. A. M. Eriyagama, Jinsen Chen, Bhaskar Halami, Yipeng Yin, Komal Chillar and Shiyue Fang*

Department of Chemistry, Michigan Technological University, 1400 Townsend Drive, Houghton, MI 49931, USA

Email: shifang@mtu.edu

\section{Table of Contents}

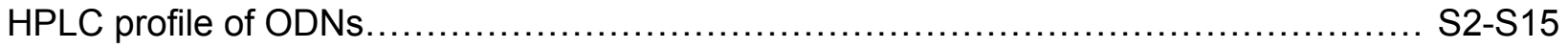

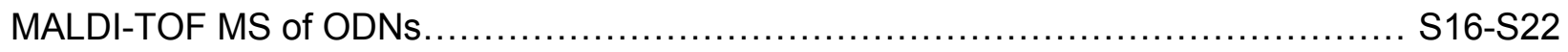

HPLC profiles of nucleosides from enzymatically digested ODNs ....................... S23-S27

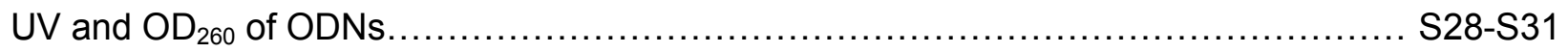

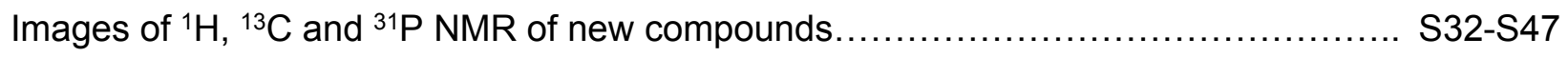



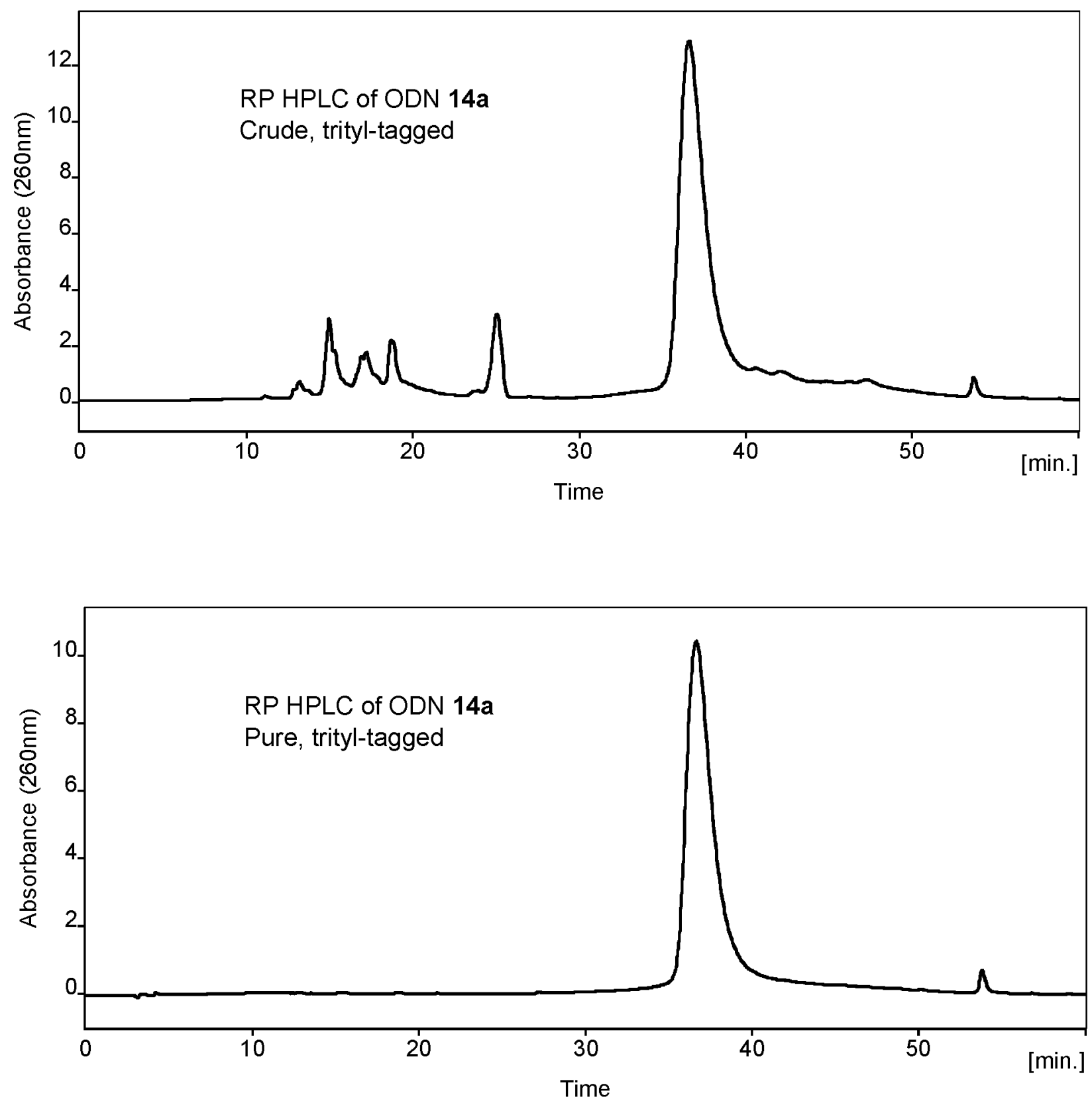

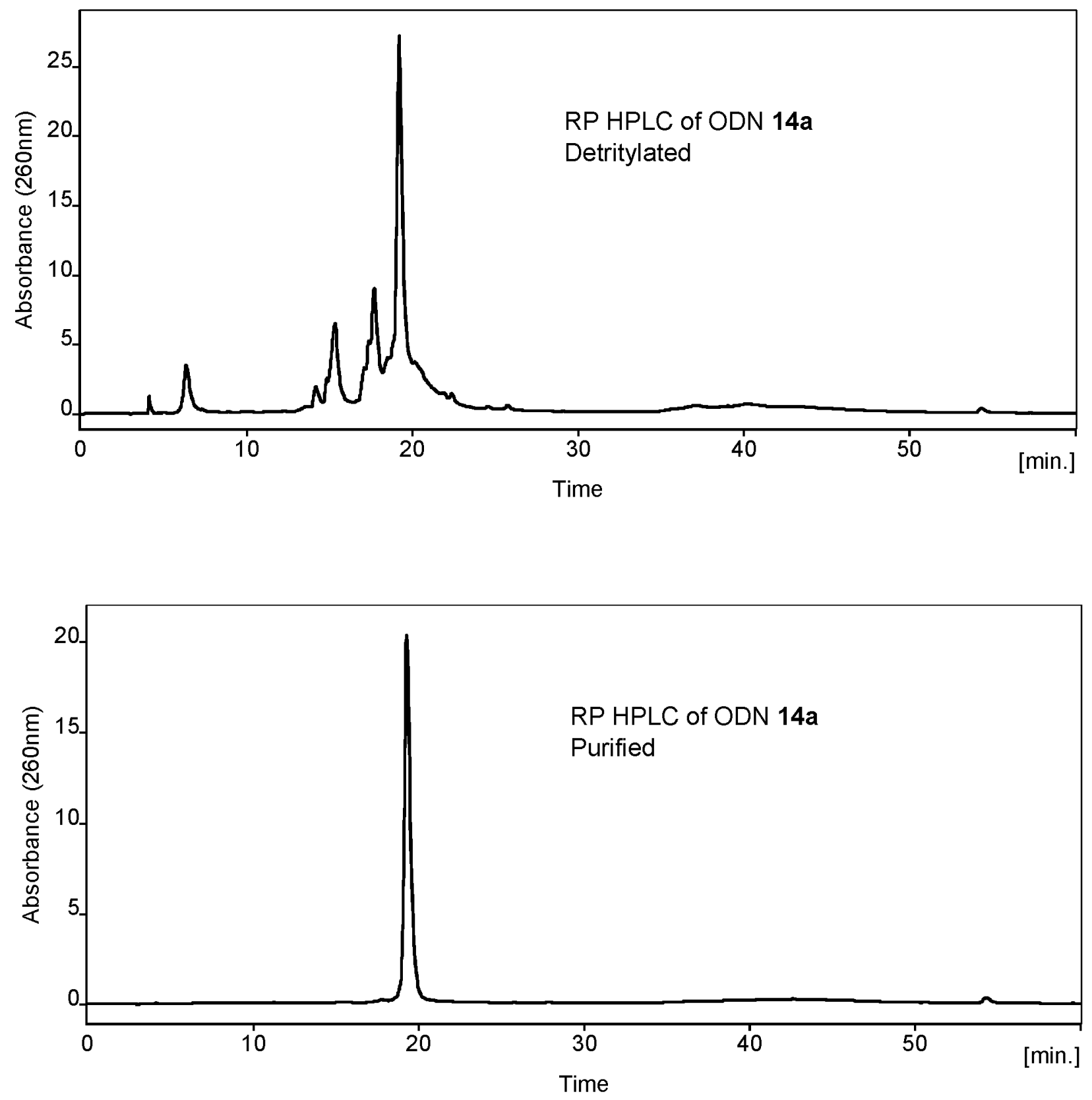

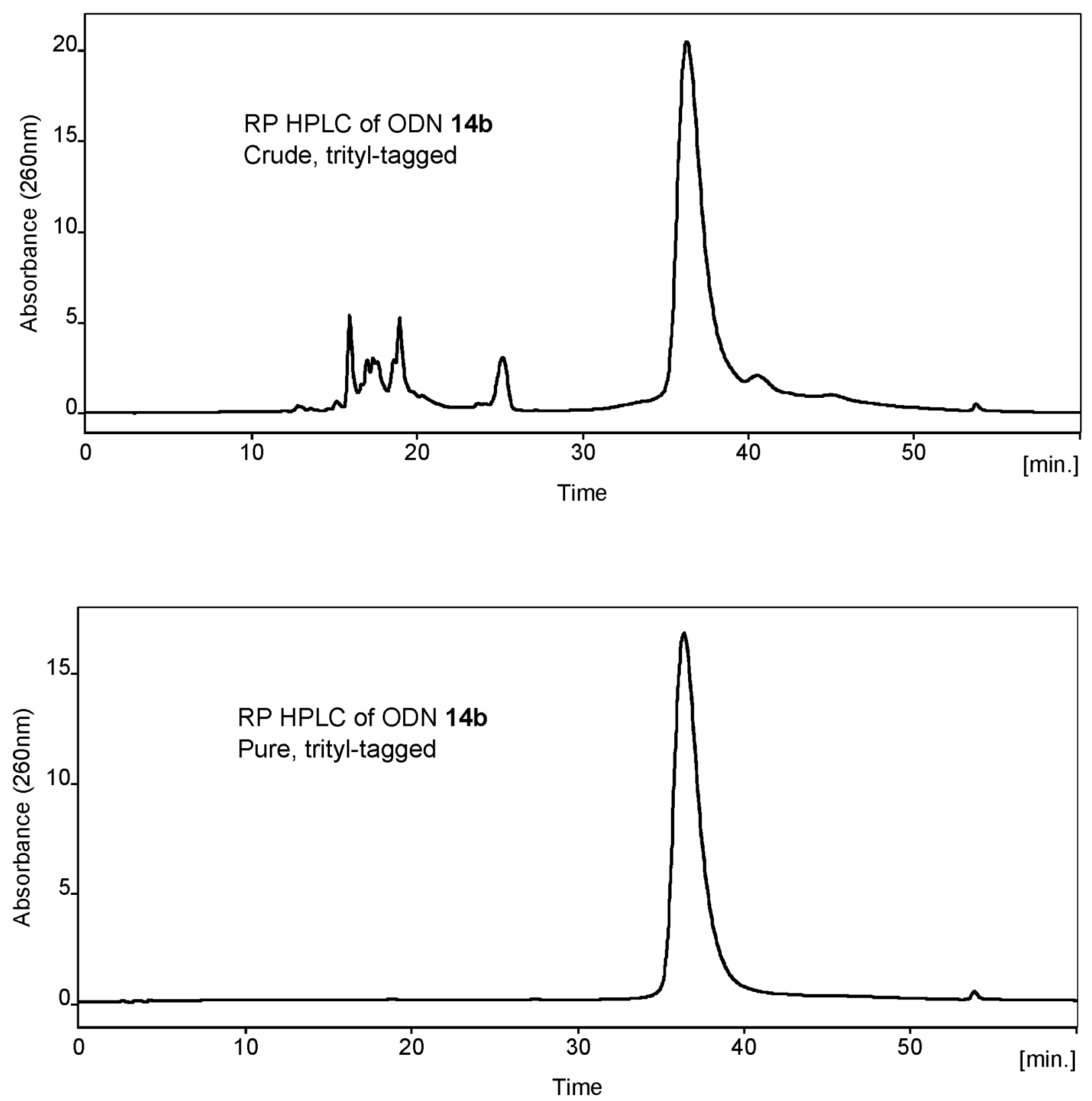

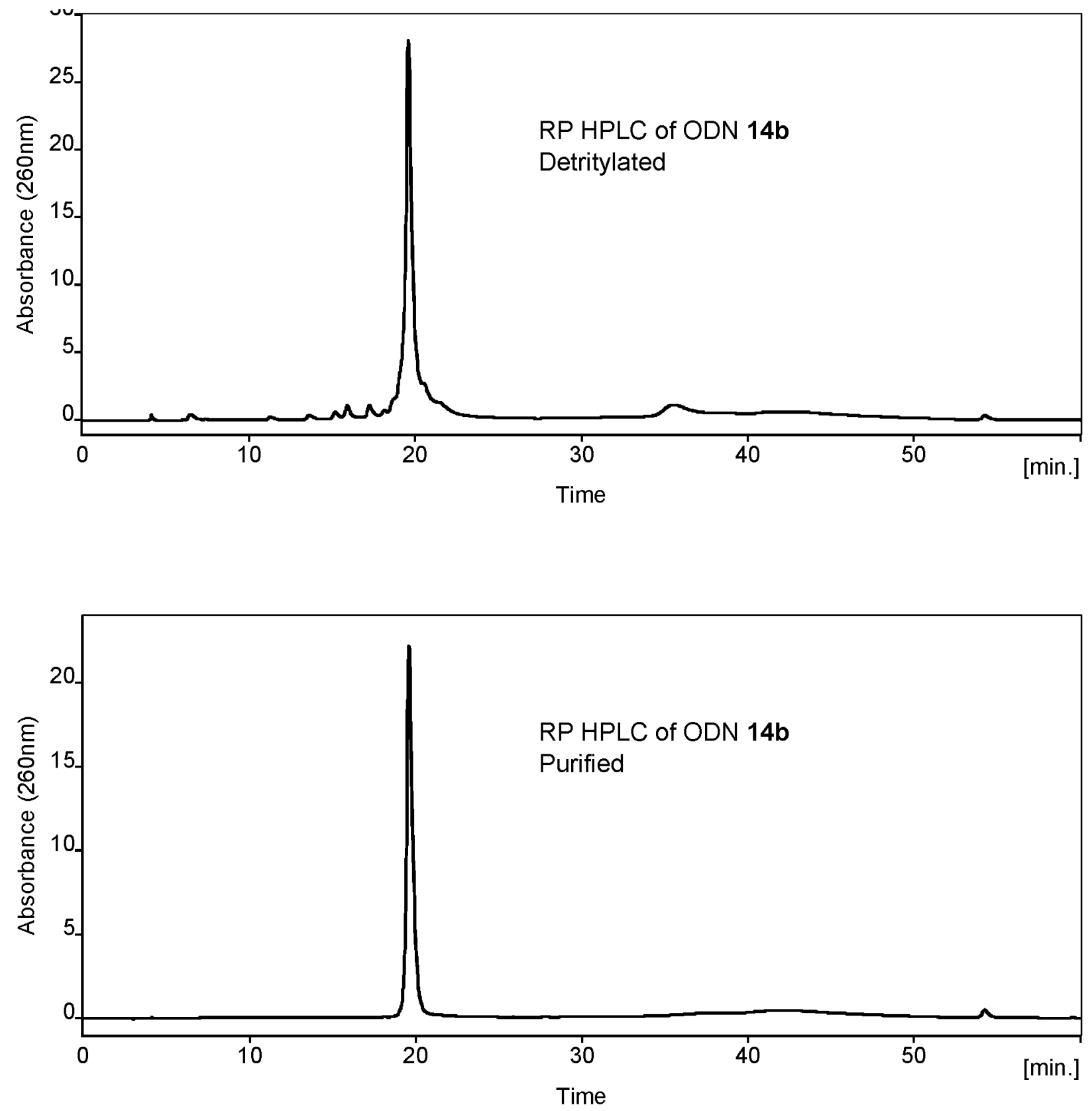

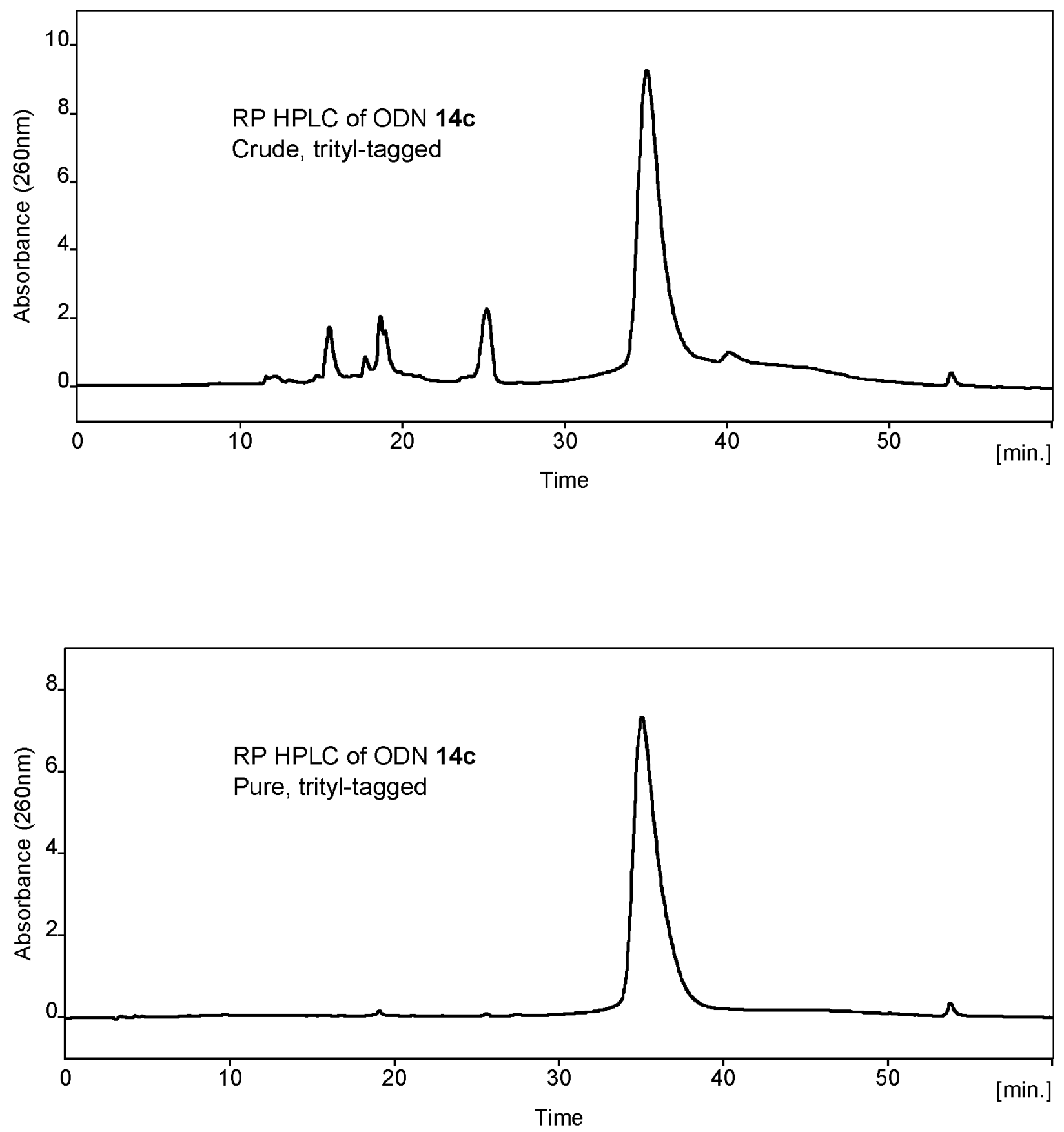

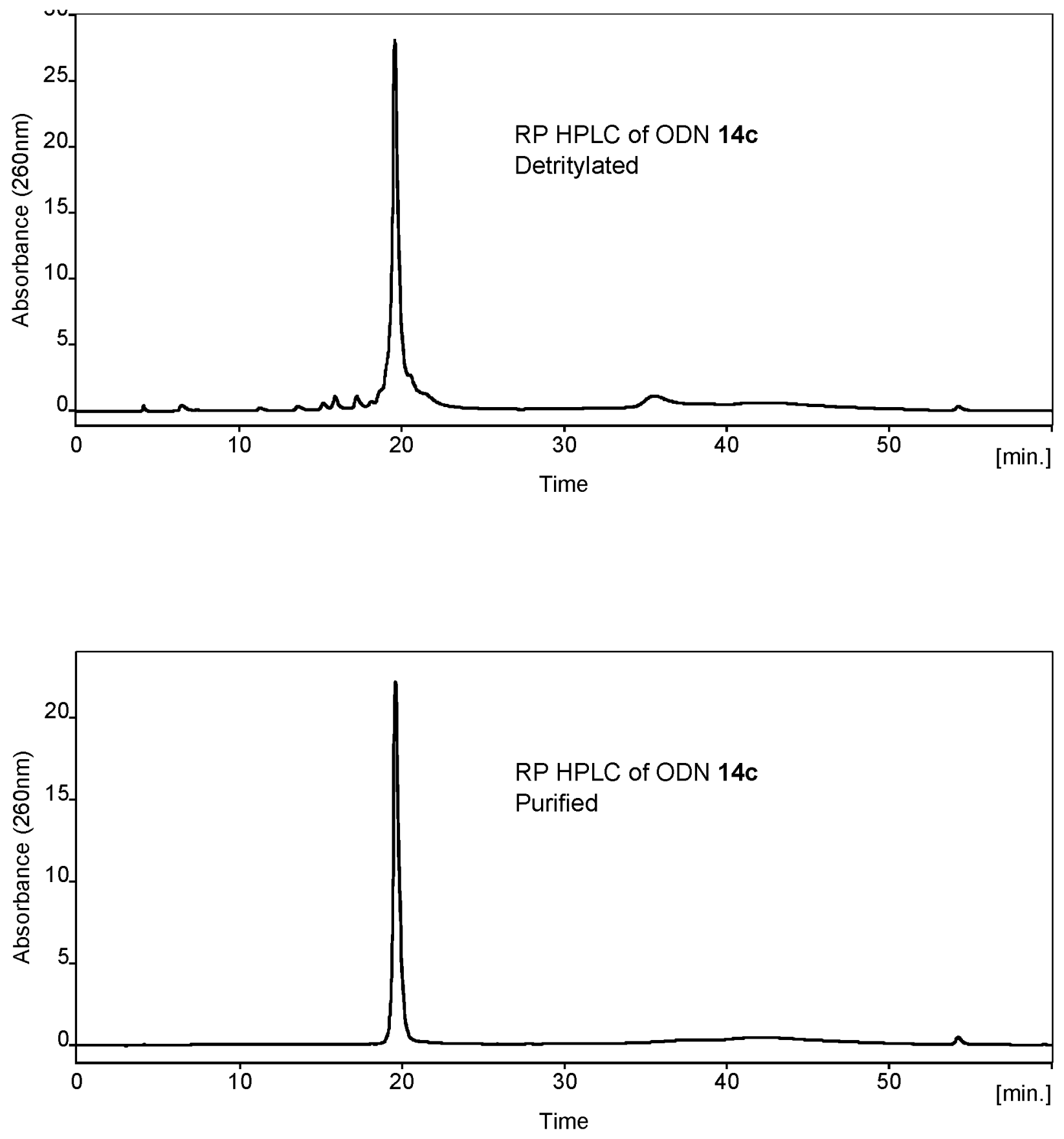

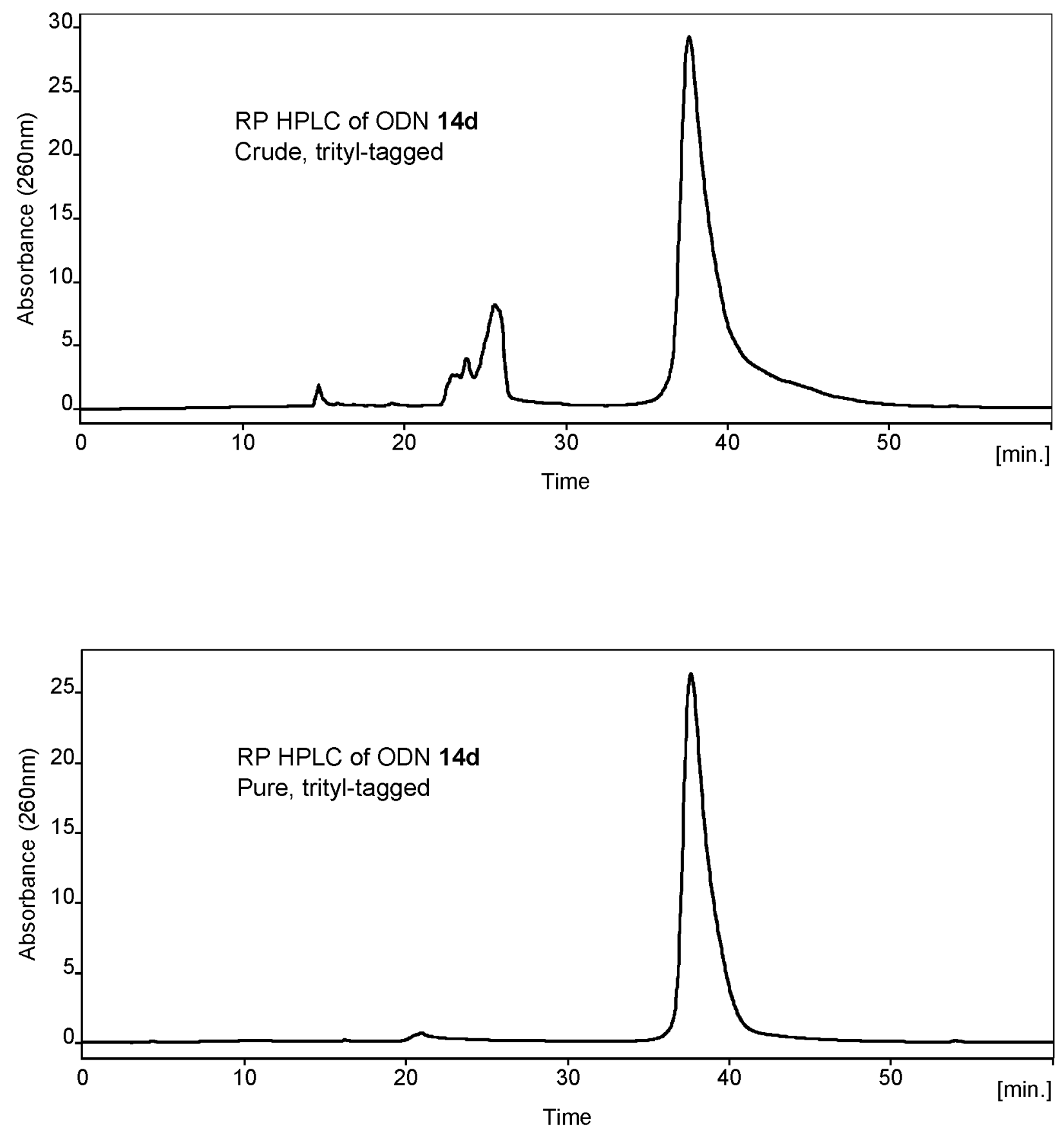

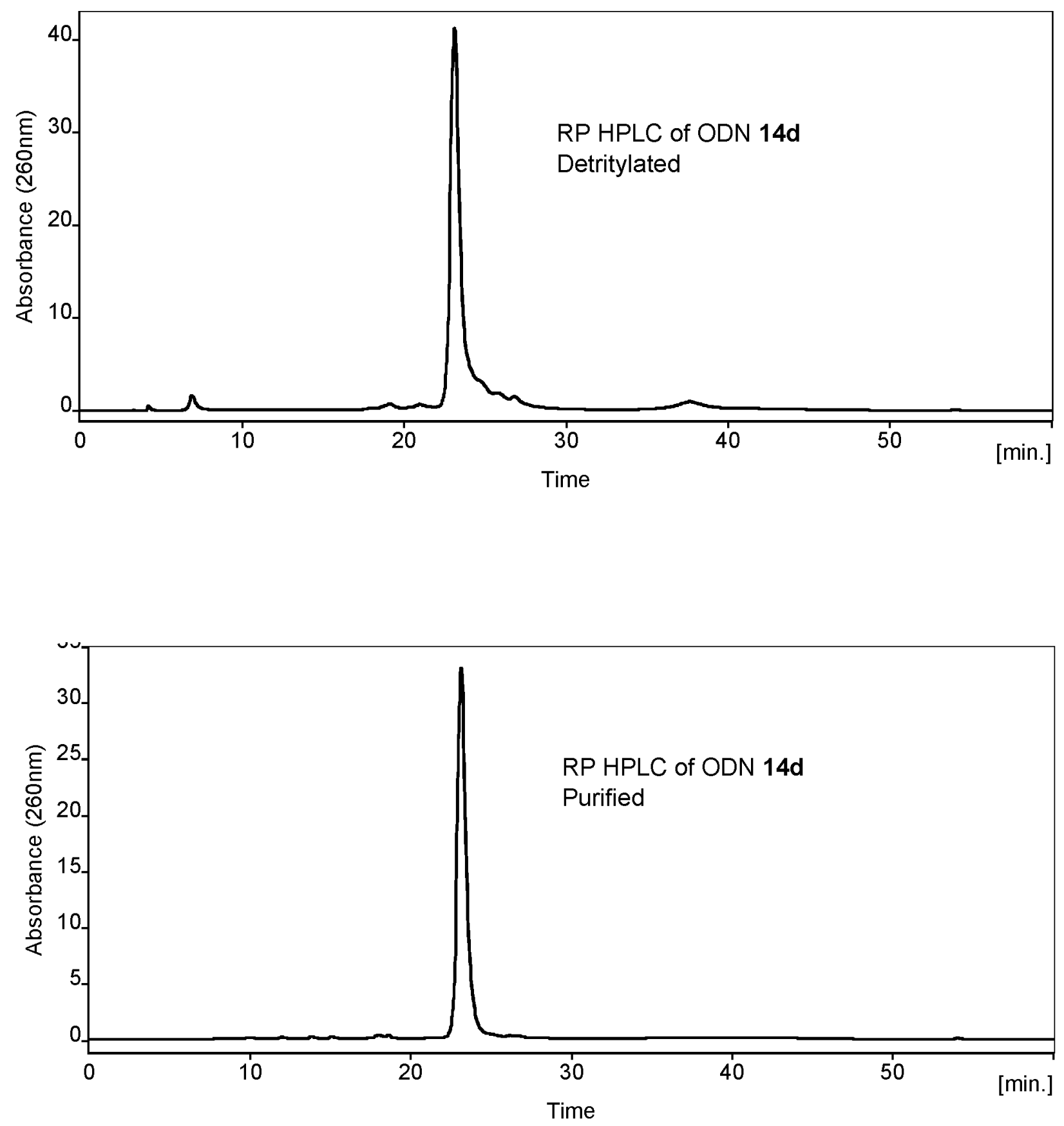

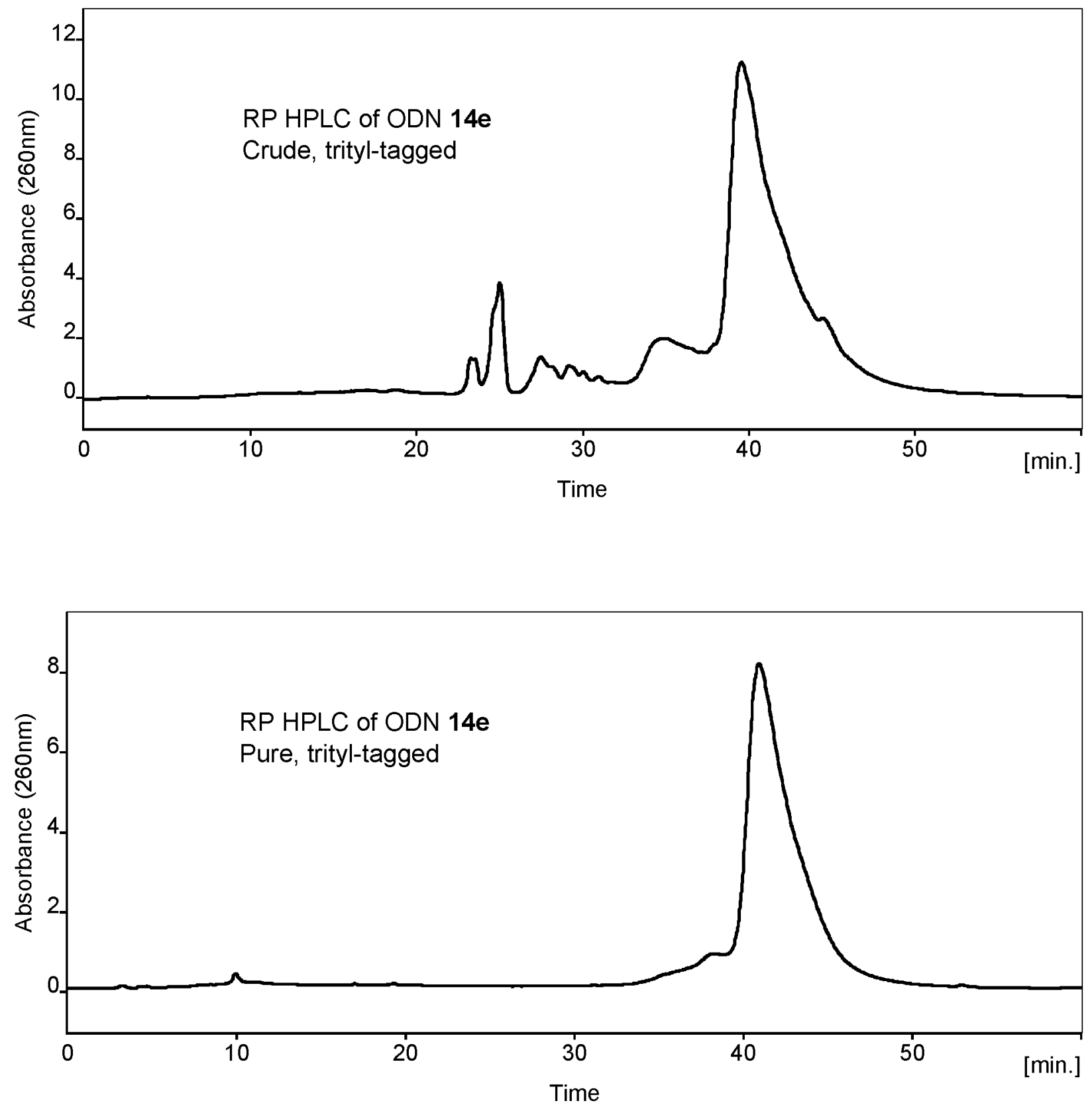

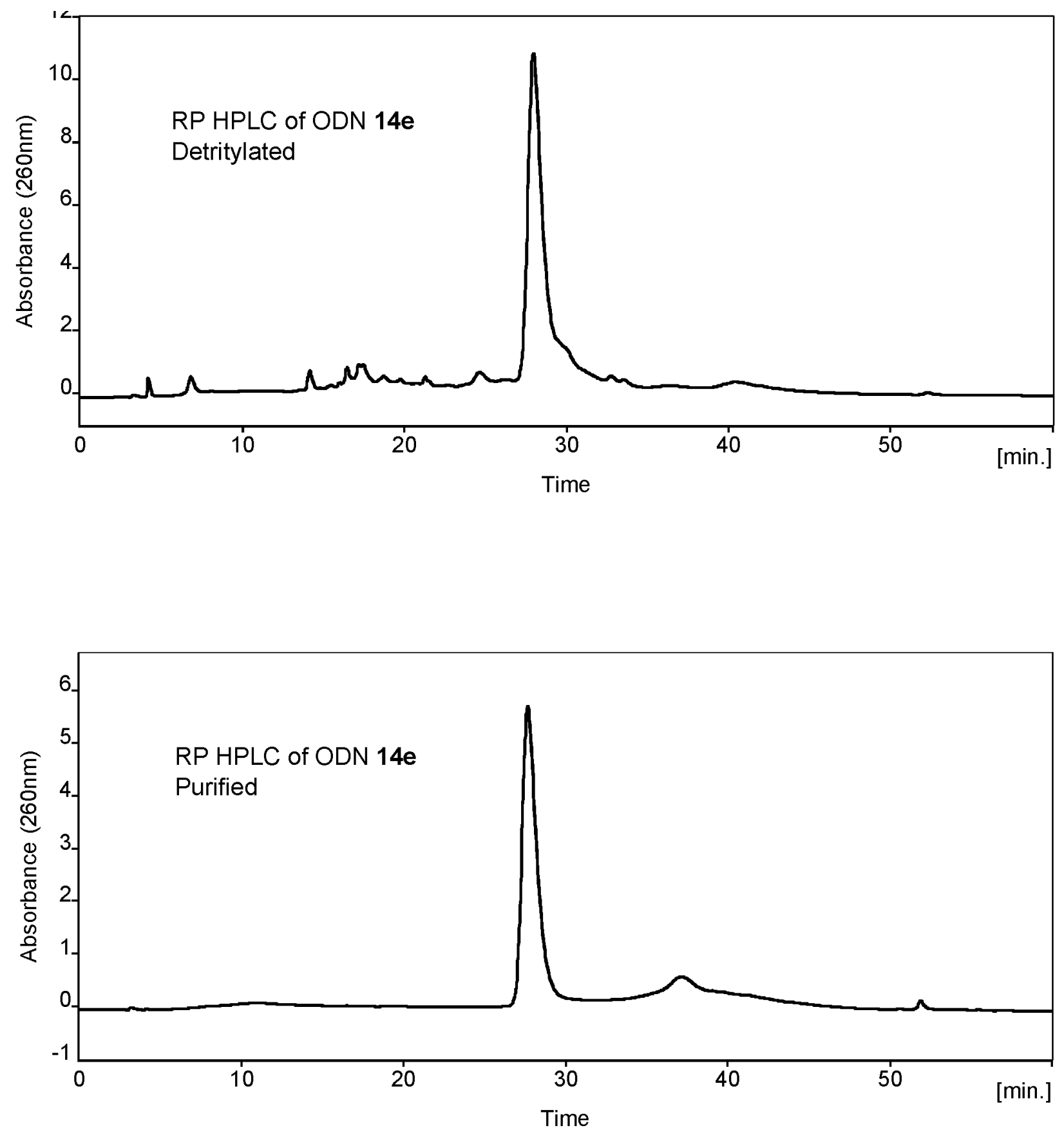

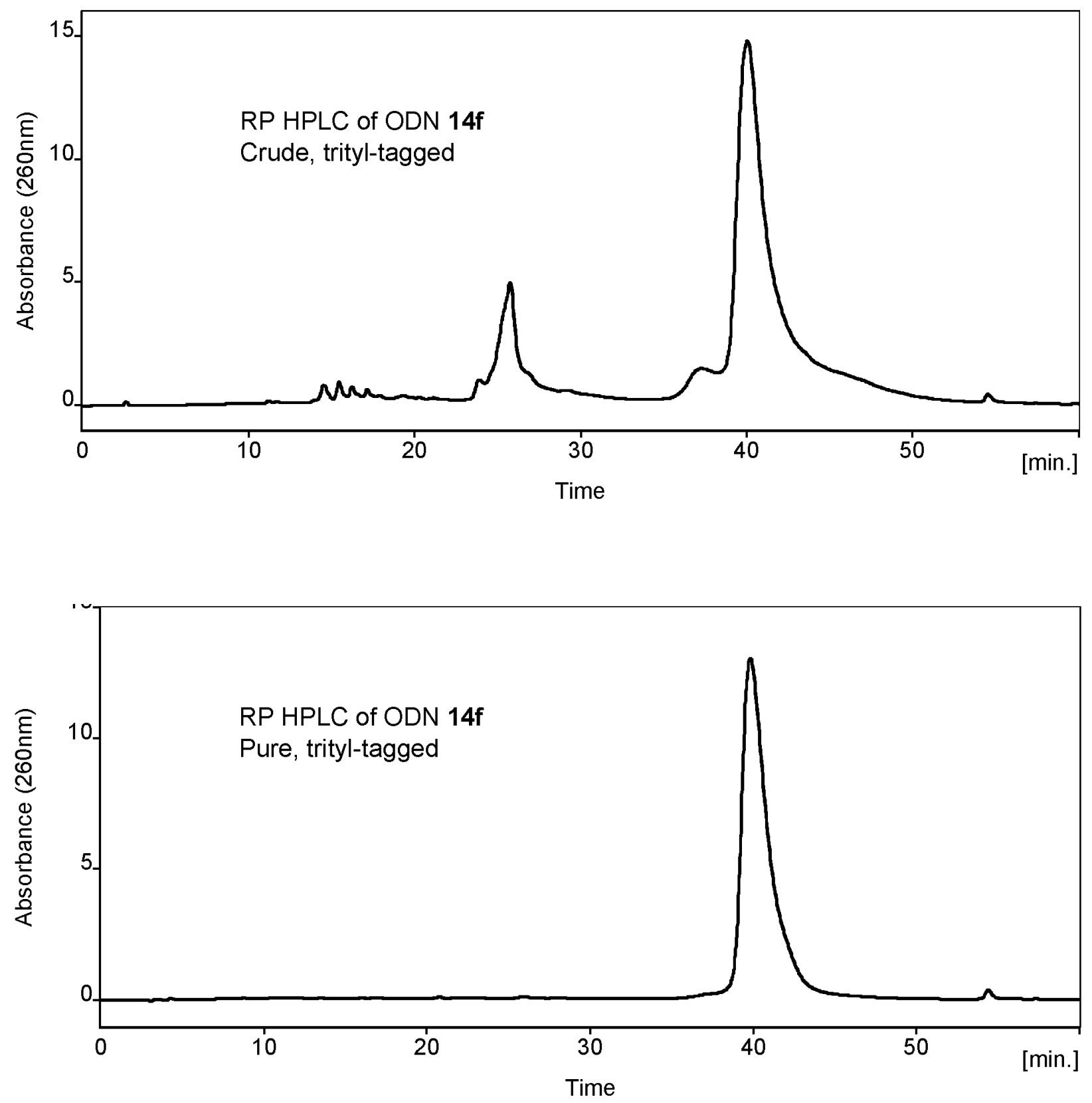

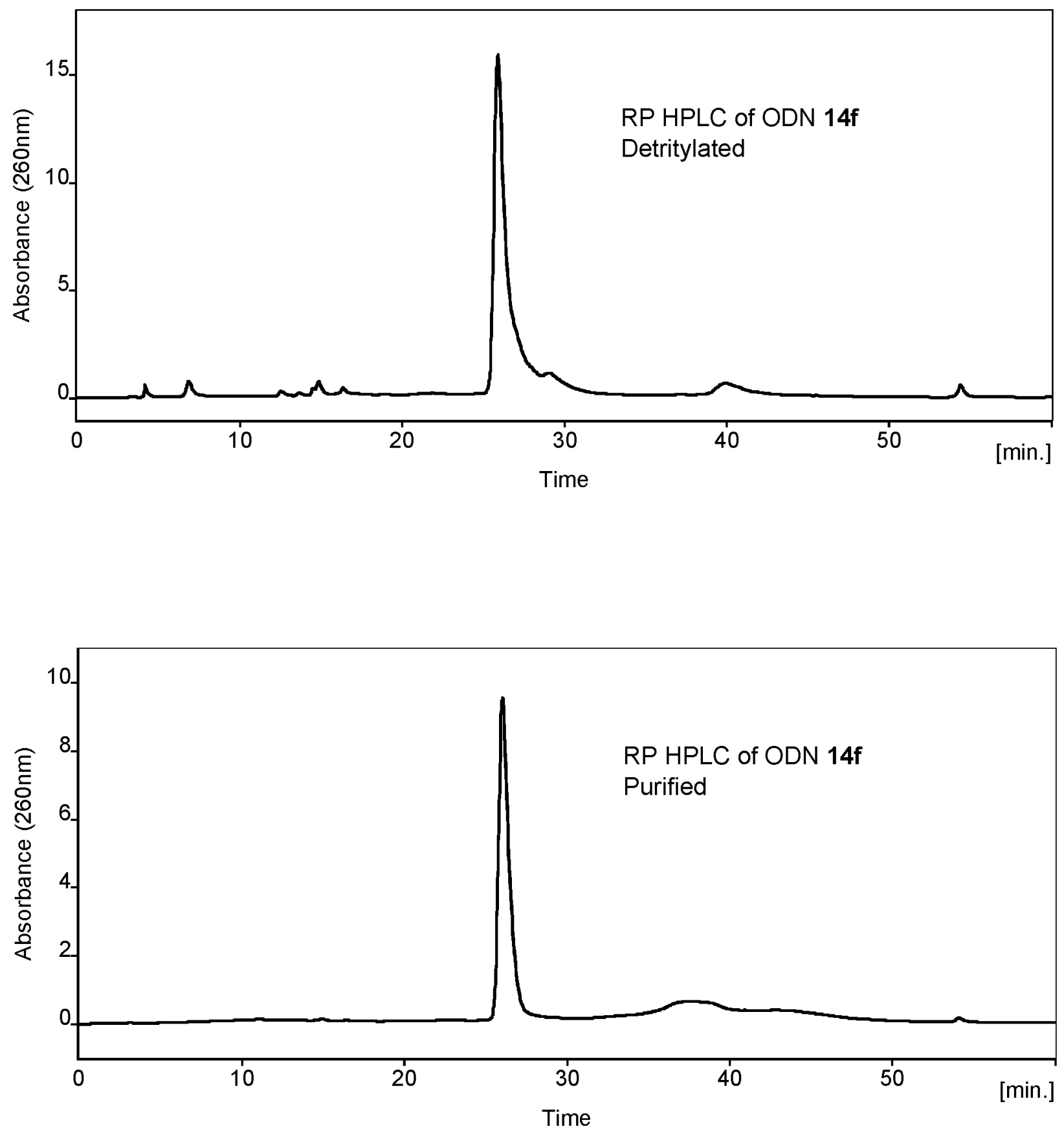

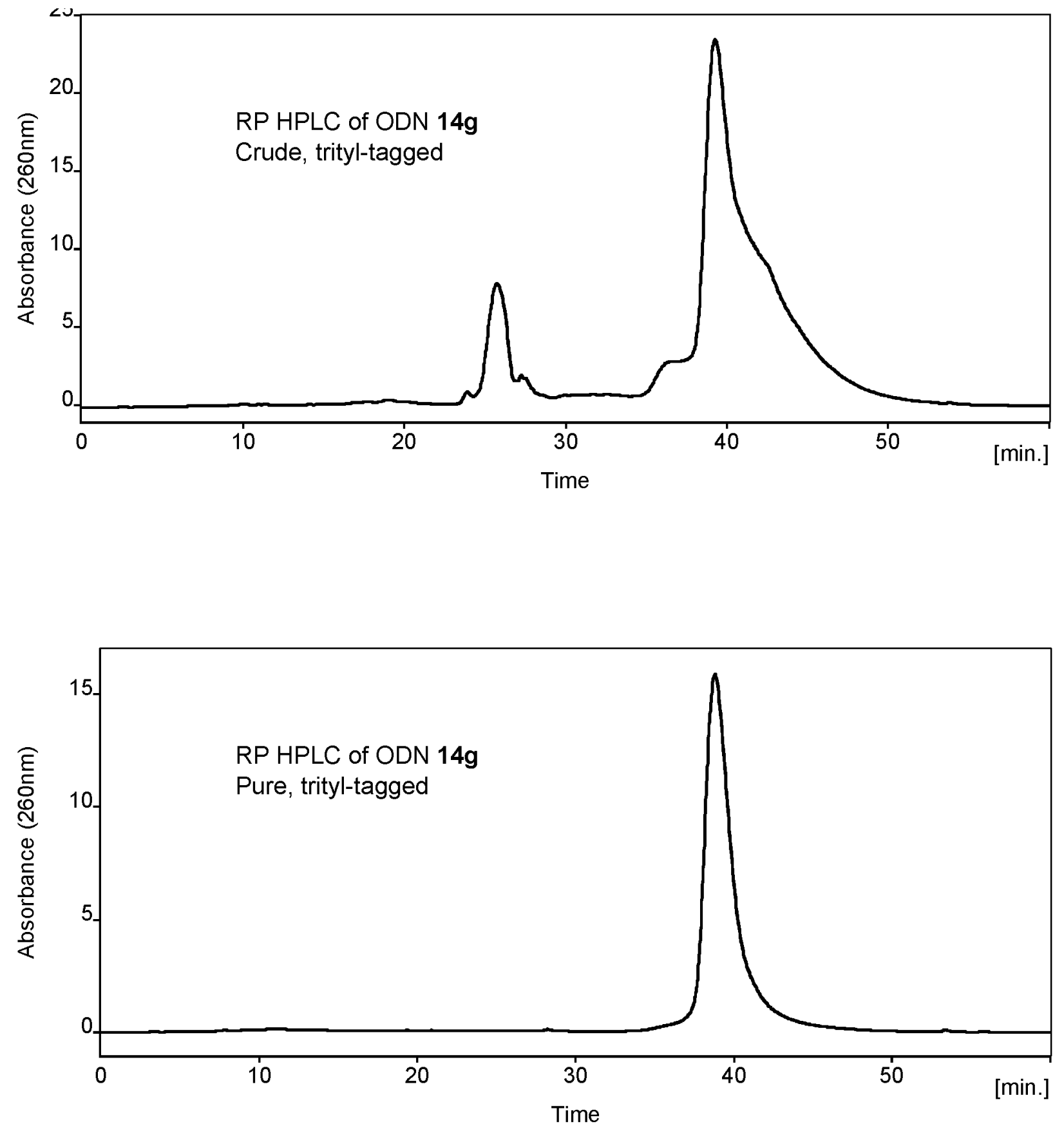

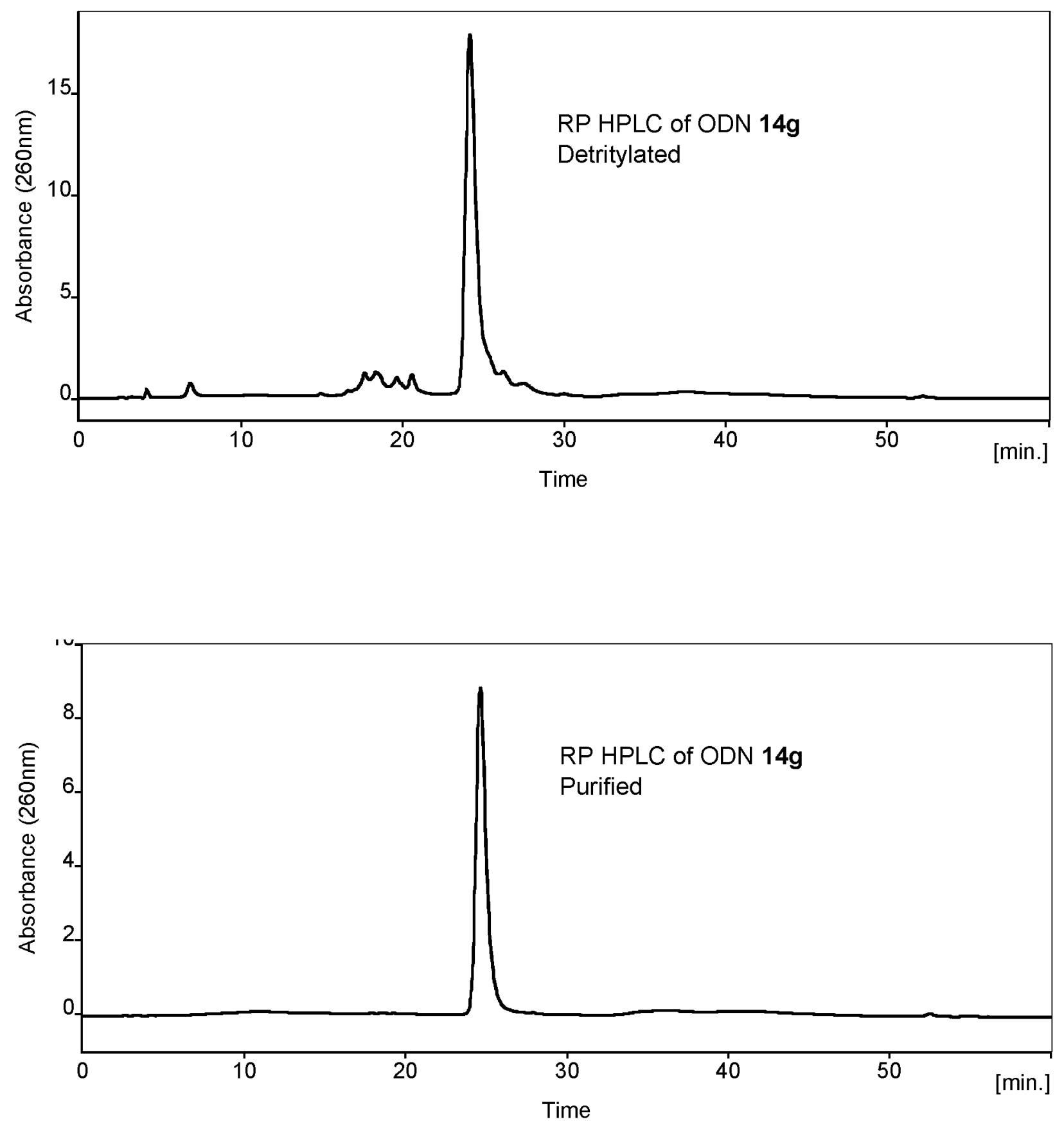

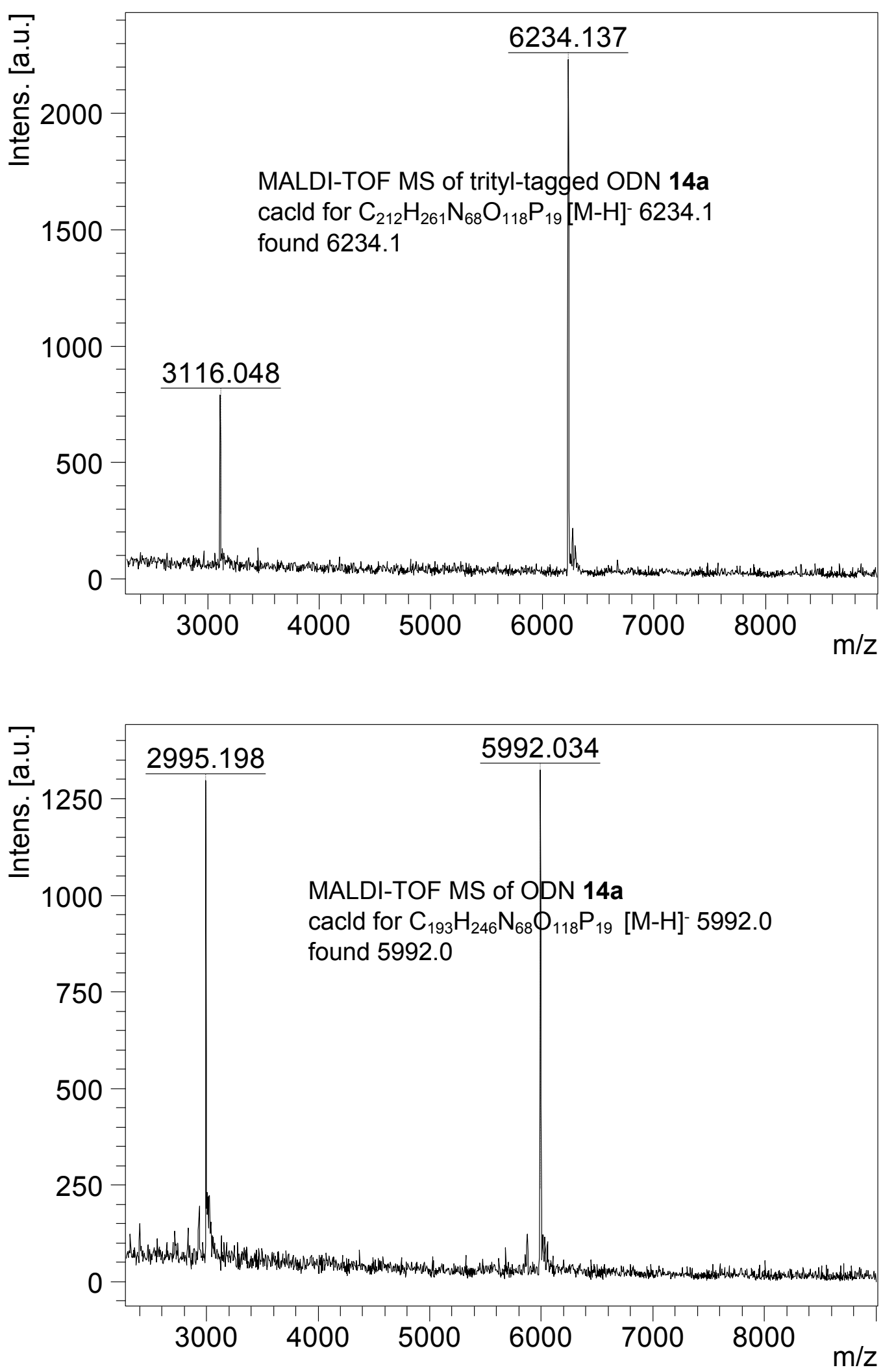

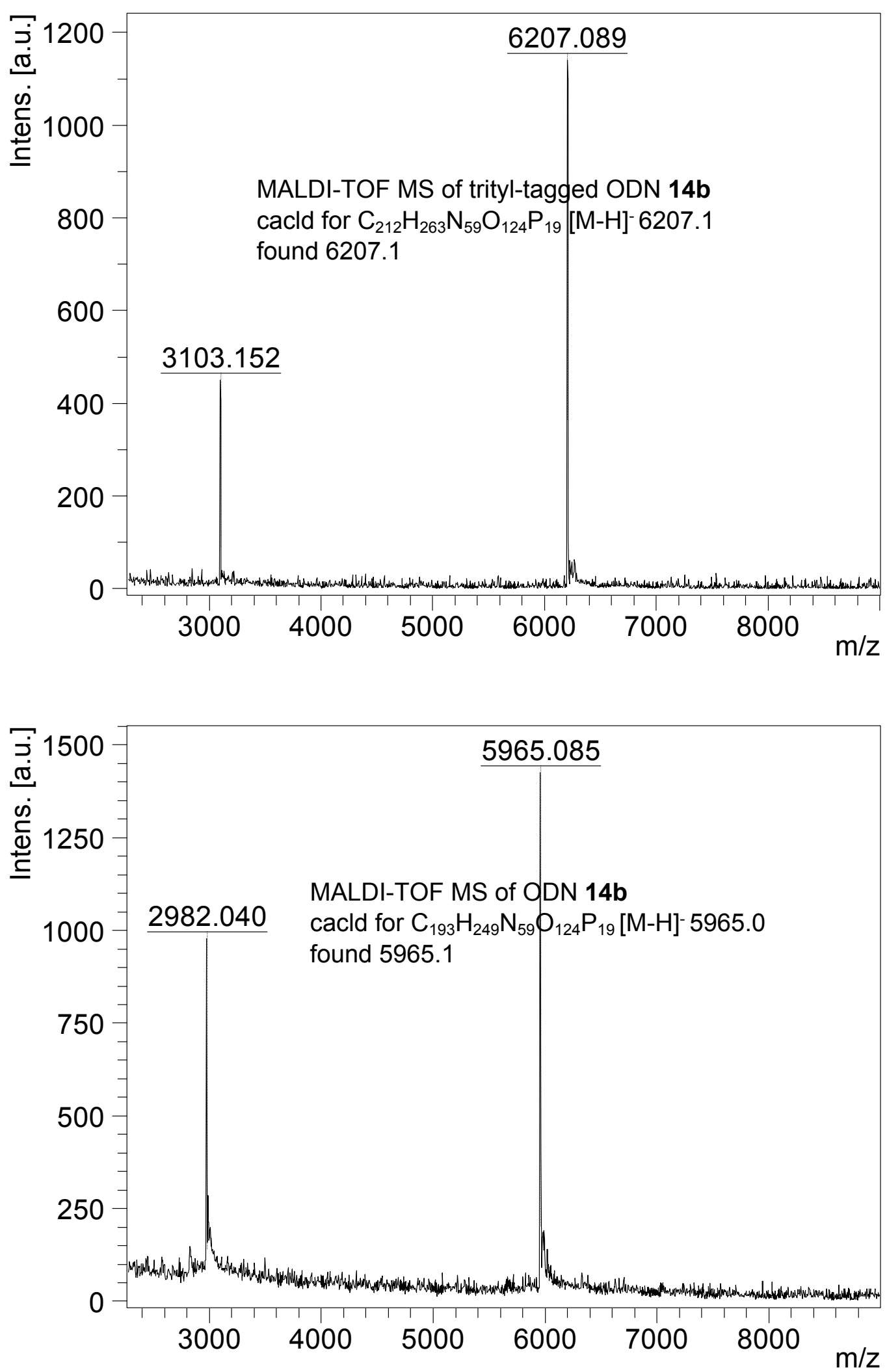

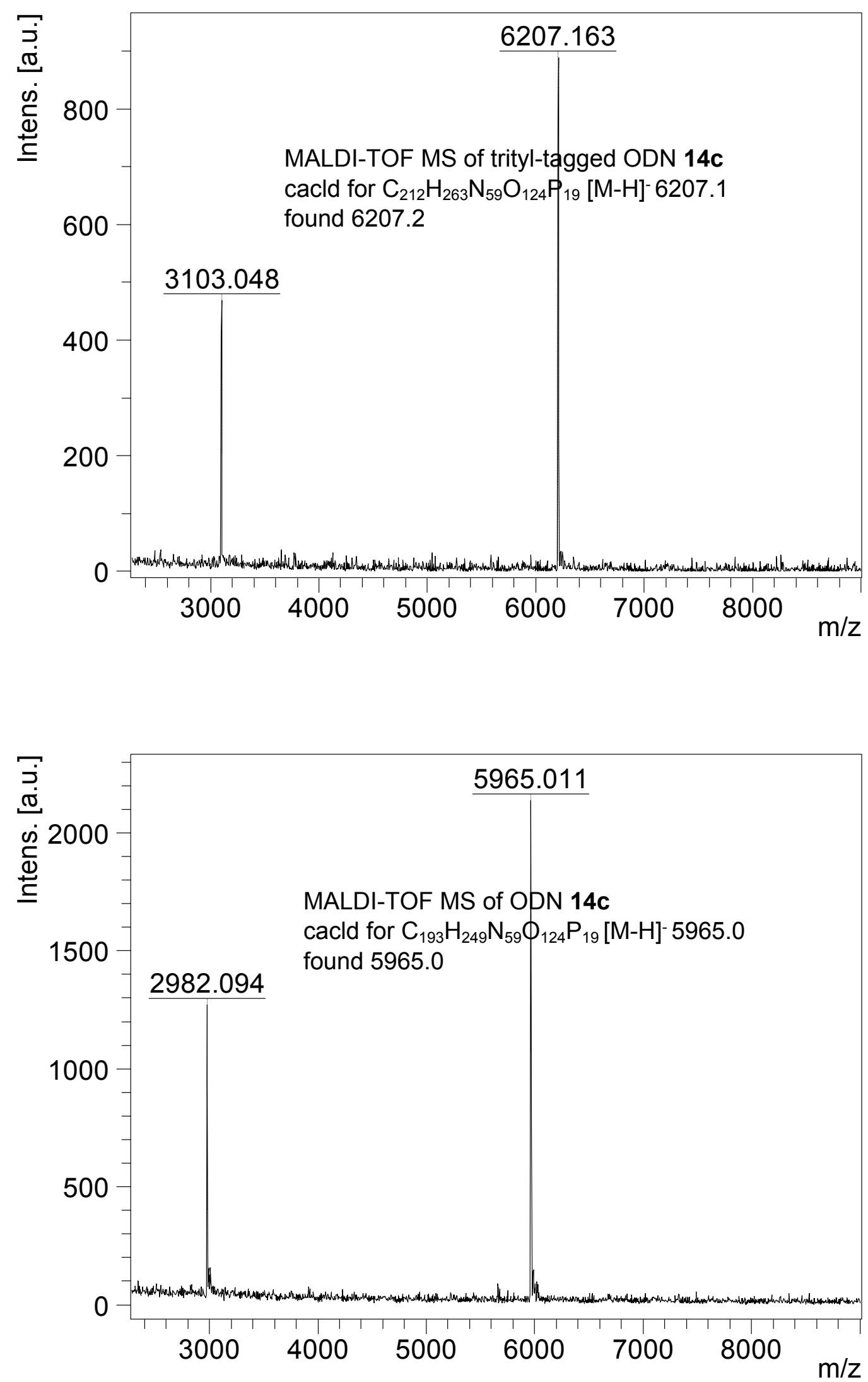

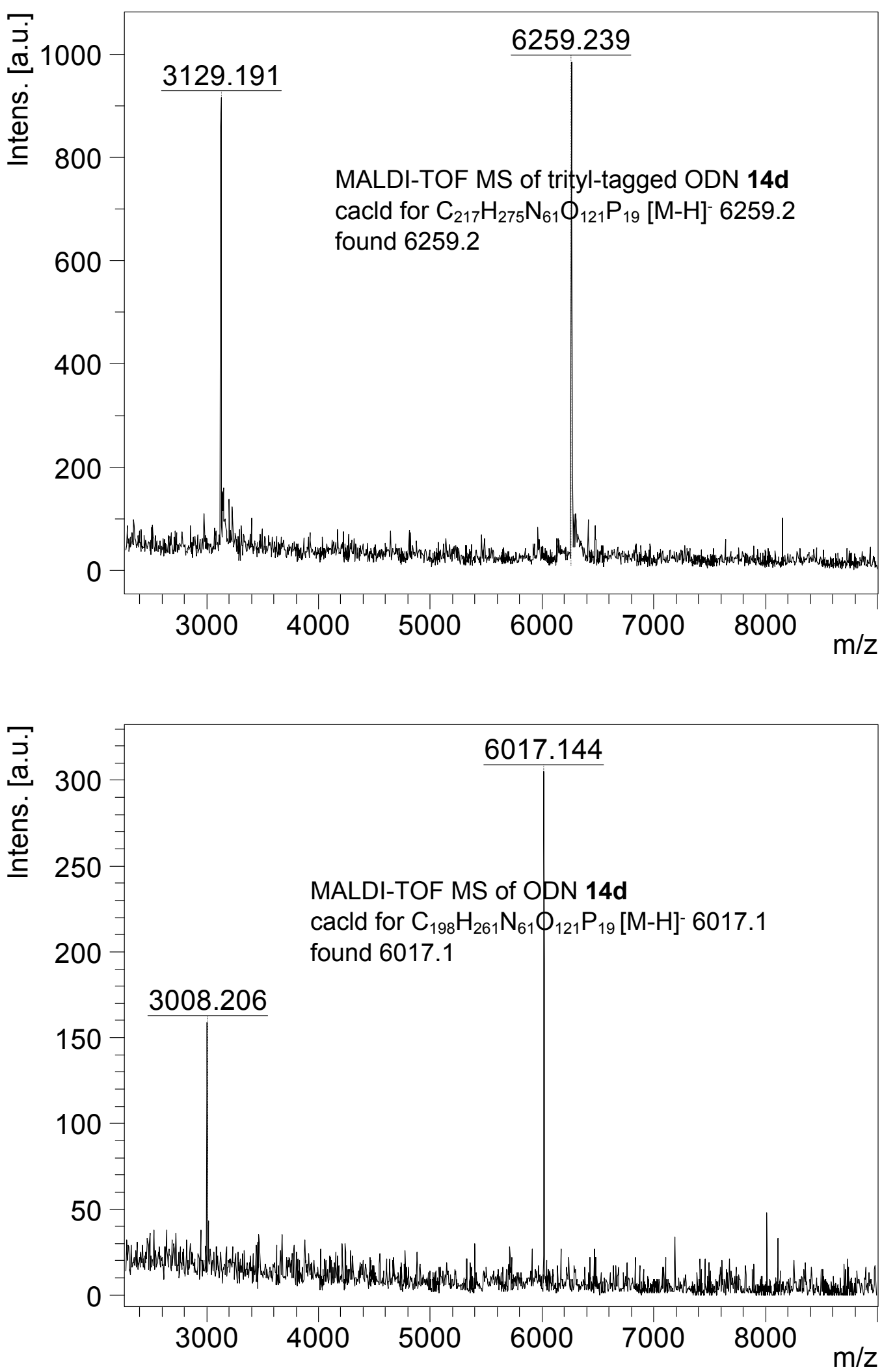

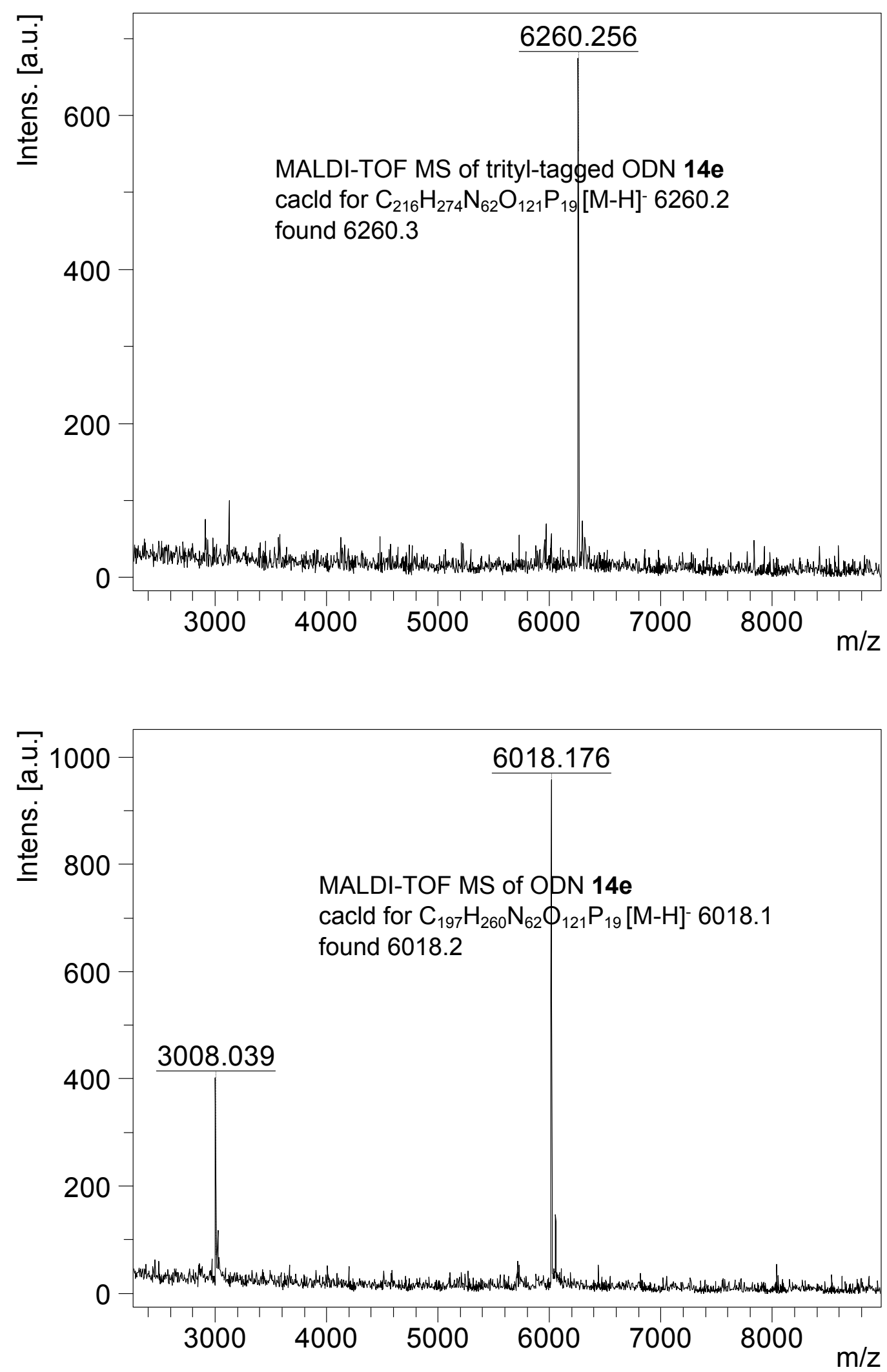

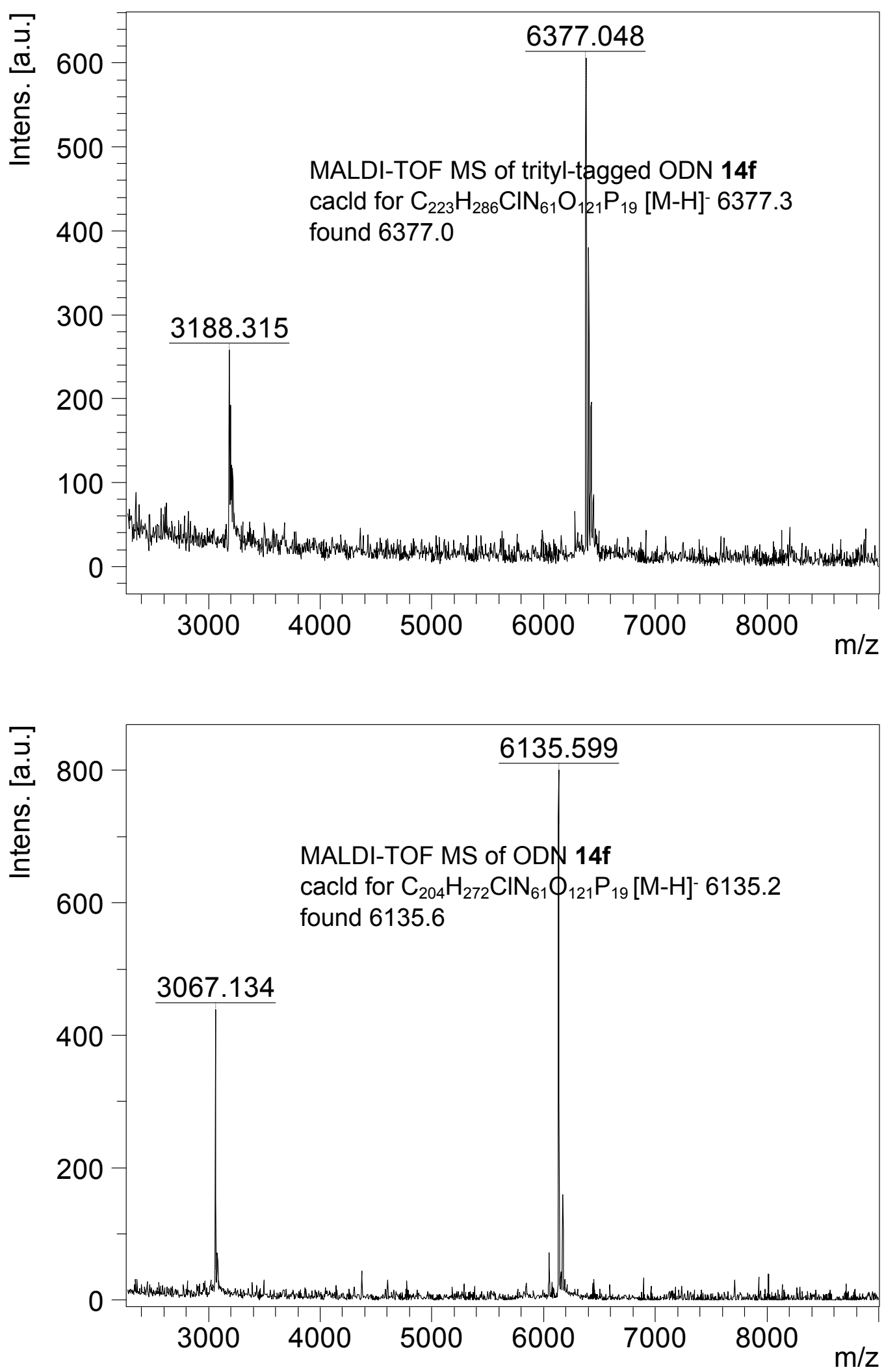

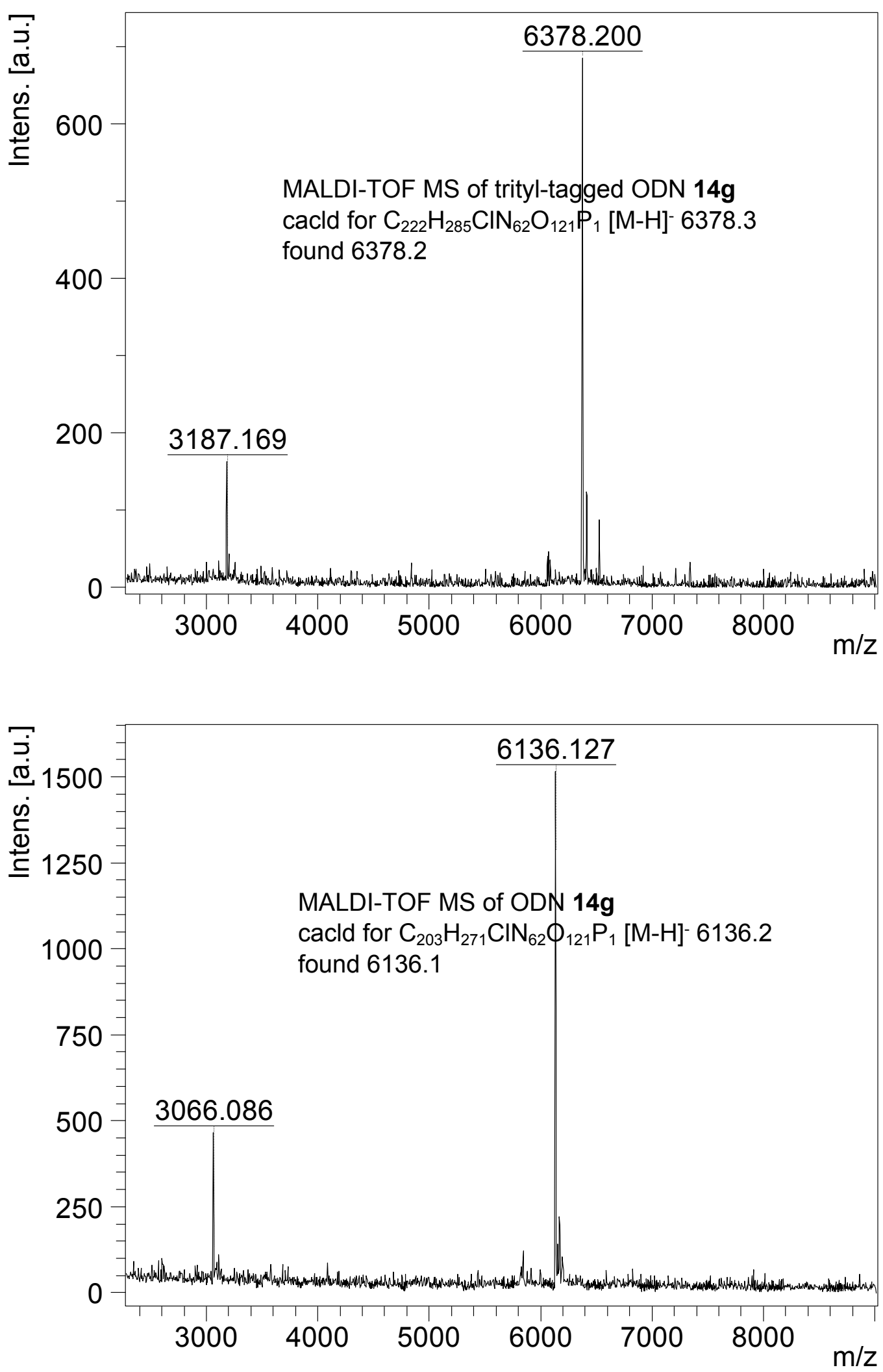


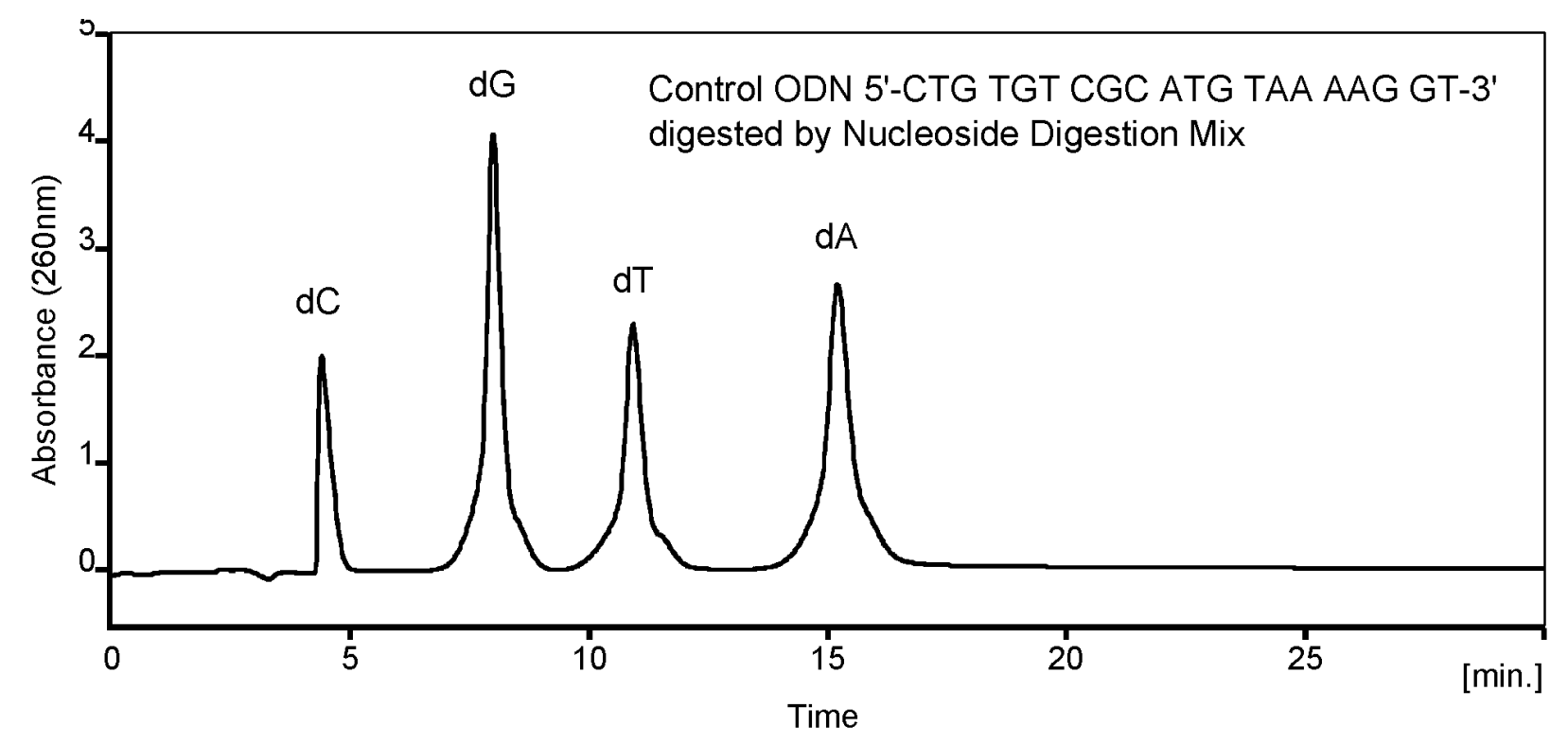

RP HPLC of nucleosides from enzyme digestion of the control ODN 5'-CTG TGT CGC ATG TAA AAG GT-3'

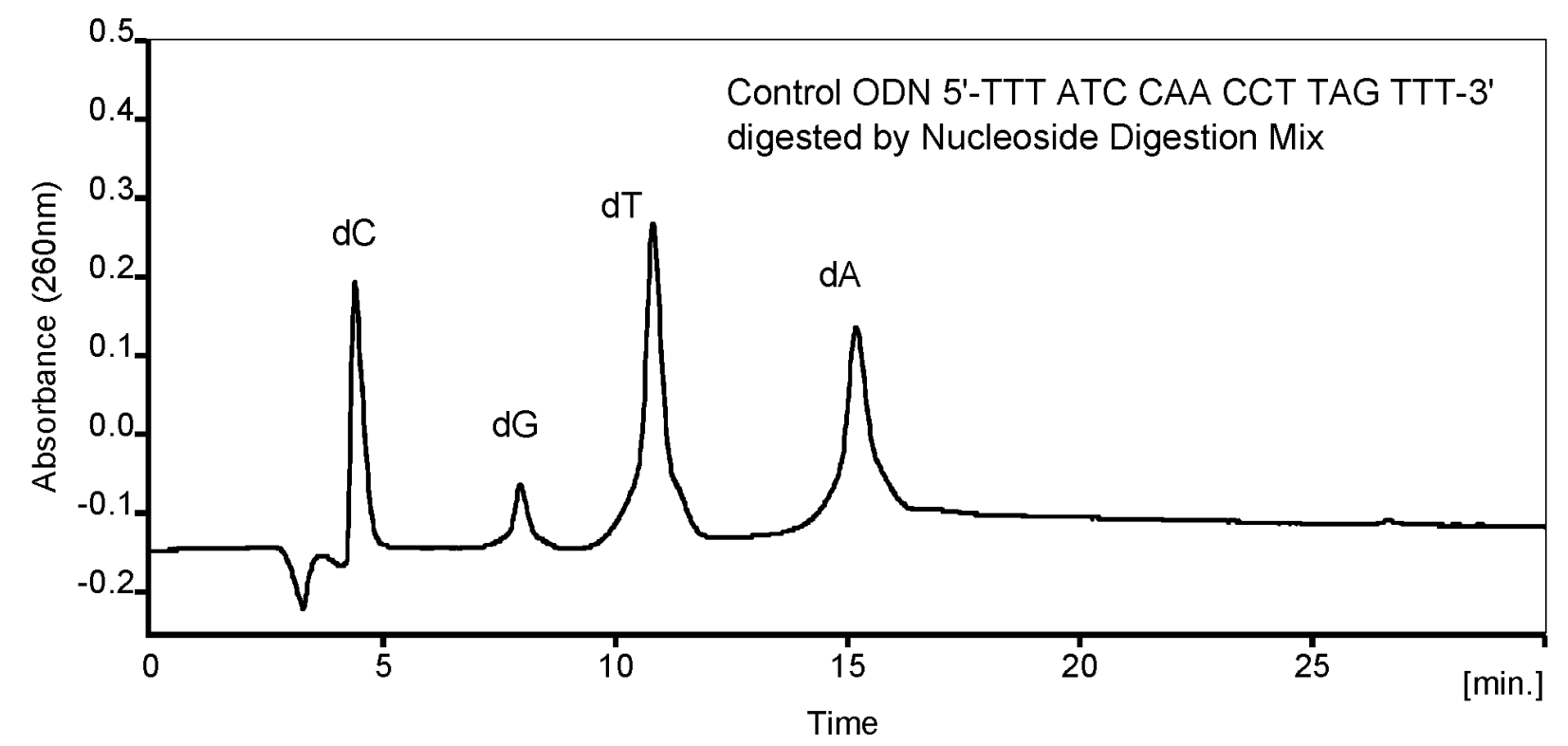

RP HPLC of nucleosides from enzyme digestion of the control ODN 5'-TTT ATC CAA CCT TAG TTT-3' 


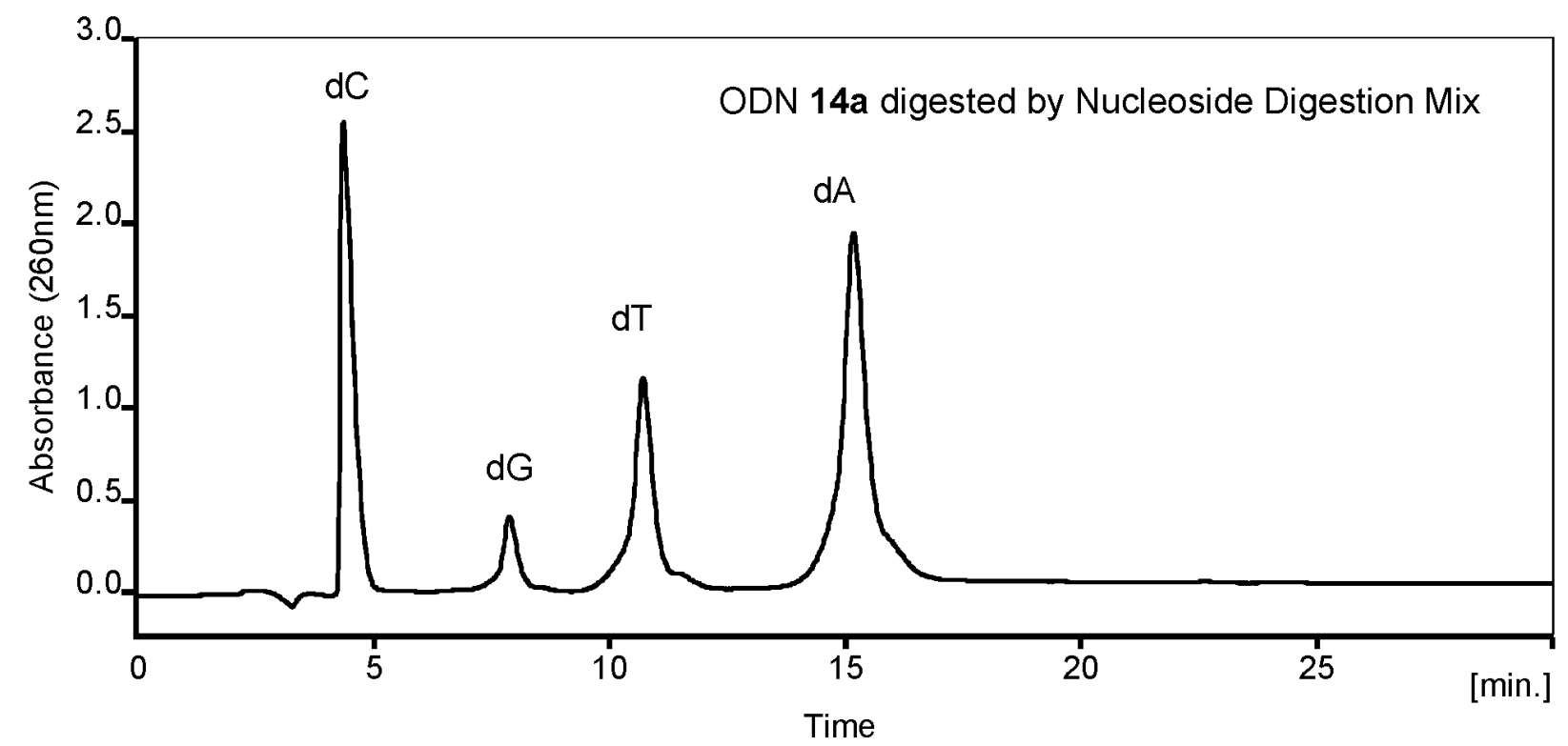

RP HPLC of nucleosides from enzyme digestion of the ODN 14a

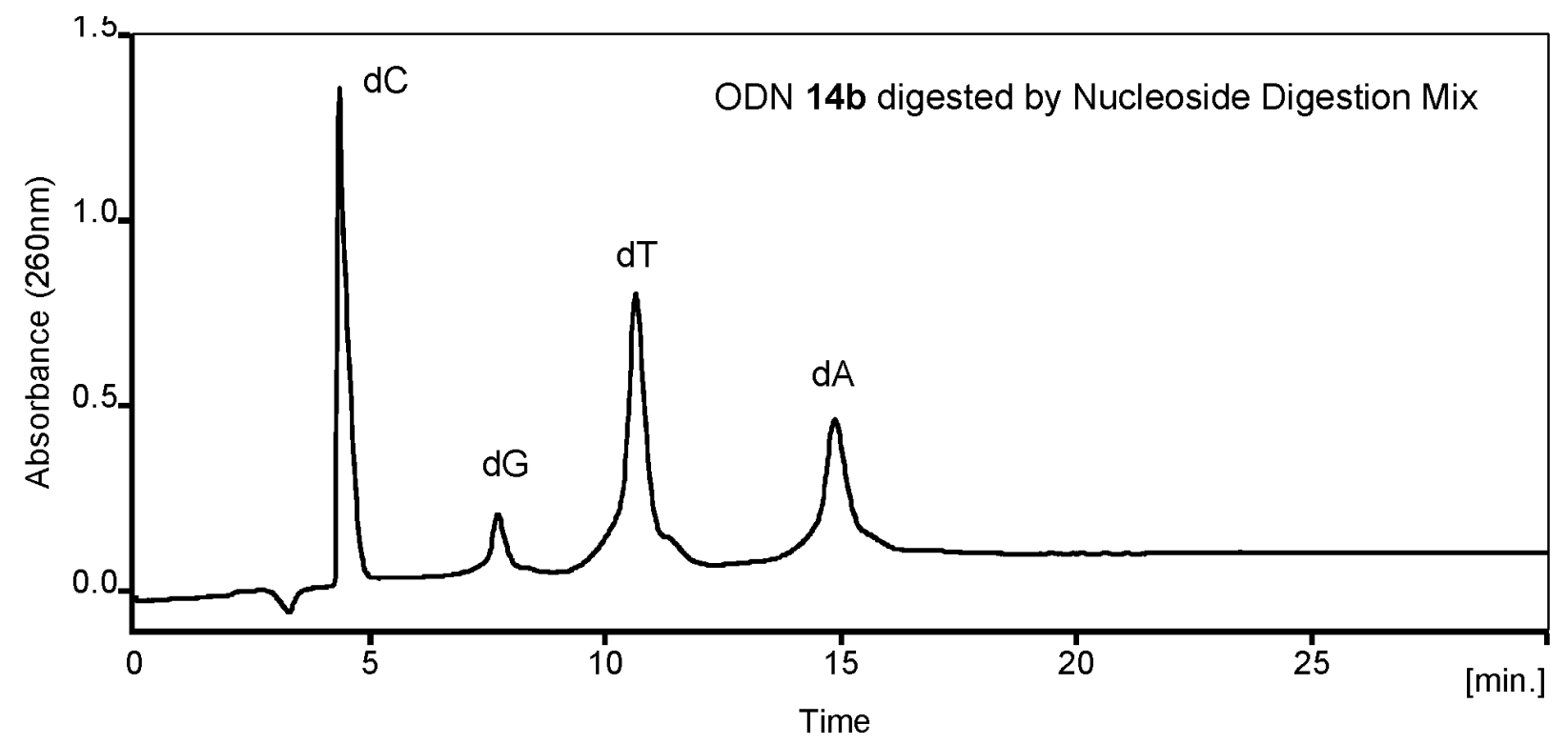

RP HPLC of nucleosides from enzyme digestion of the ODN 14b 


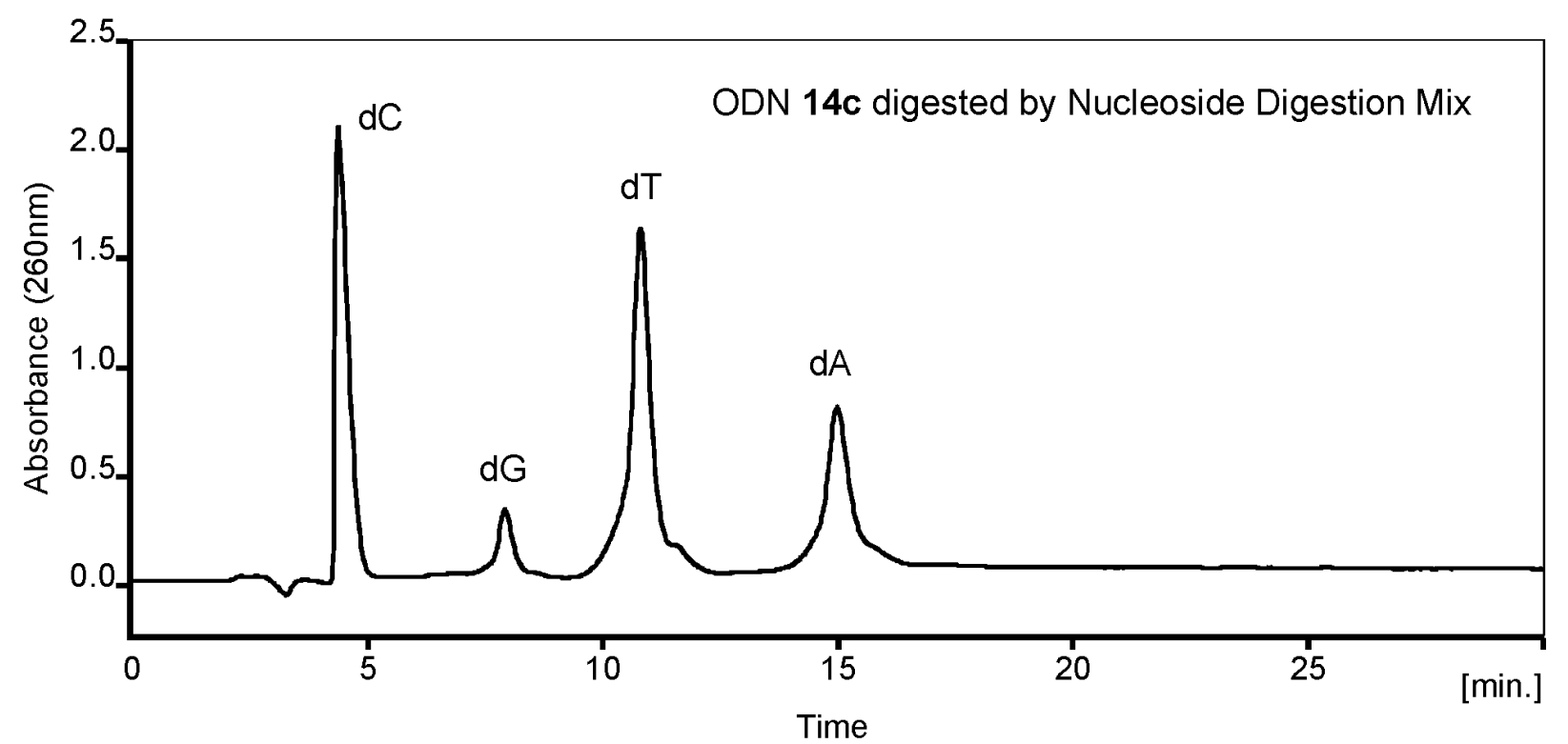

RP HPLC of nucleosides from enzyme digestion of the ODN $14 c$

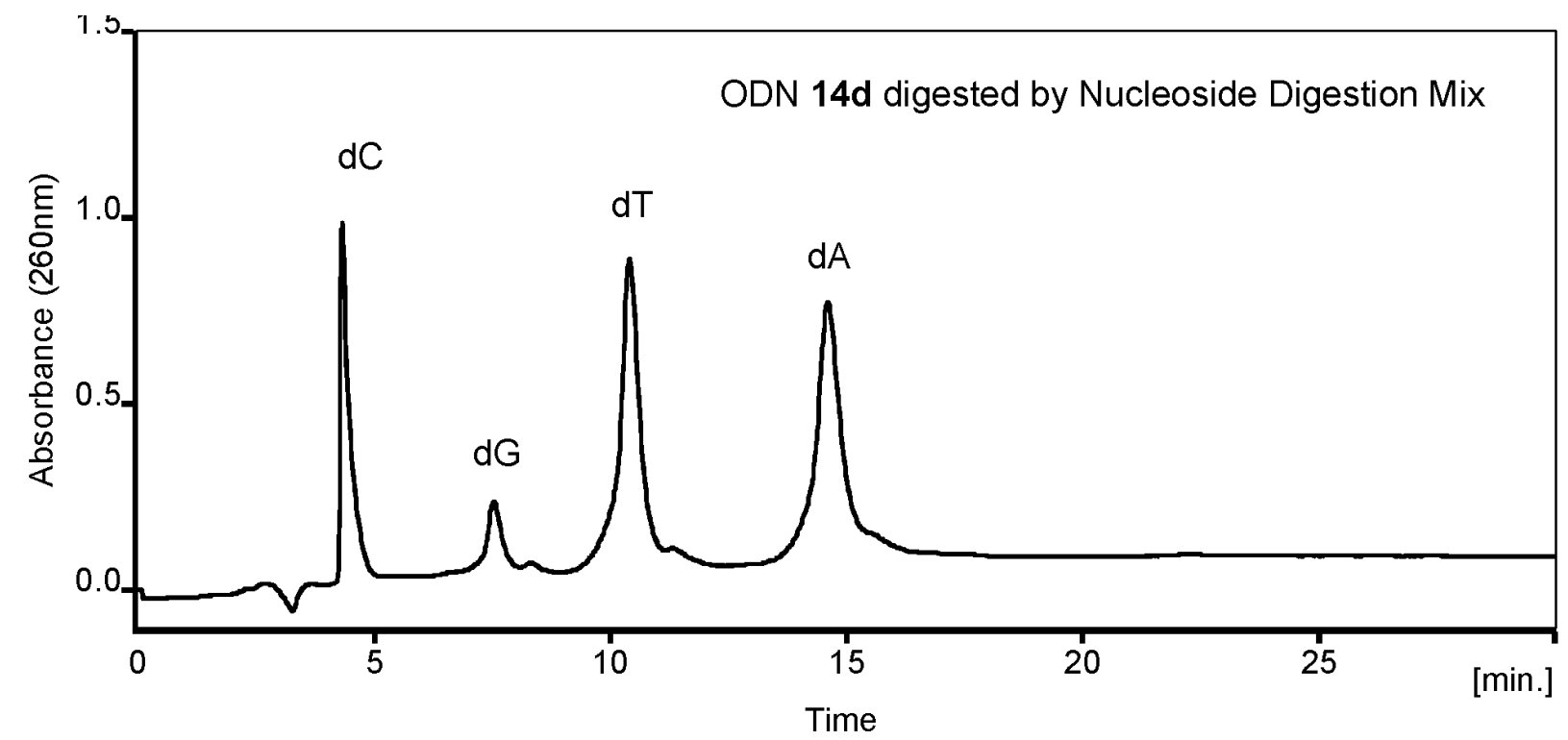

RP HPLC of nucleosides from enzyme digestion of the ODN 14d 


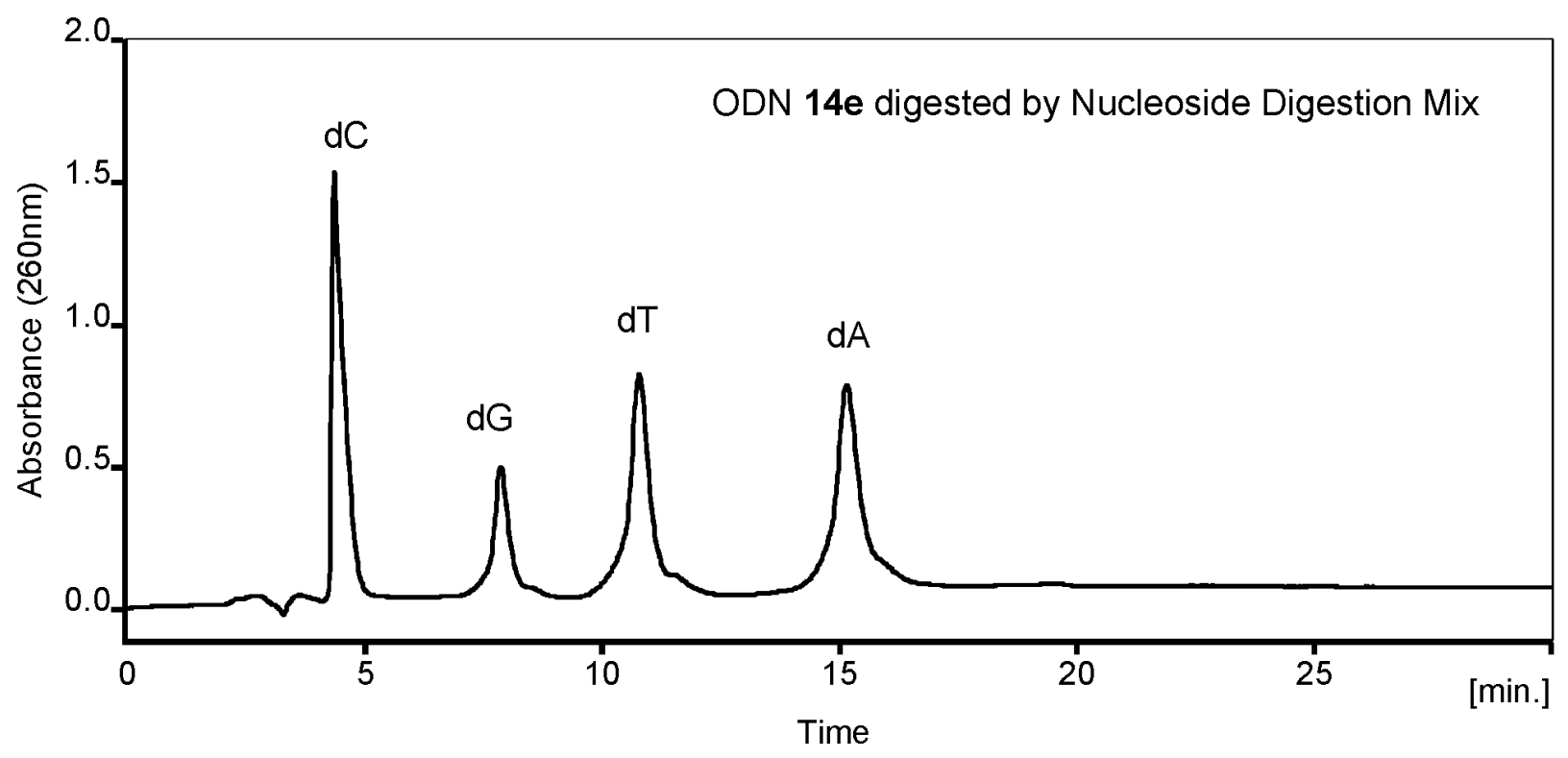

RP HPLC of nucleosides from enzyme digestion of the ODN 14e

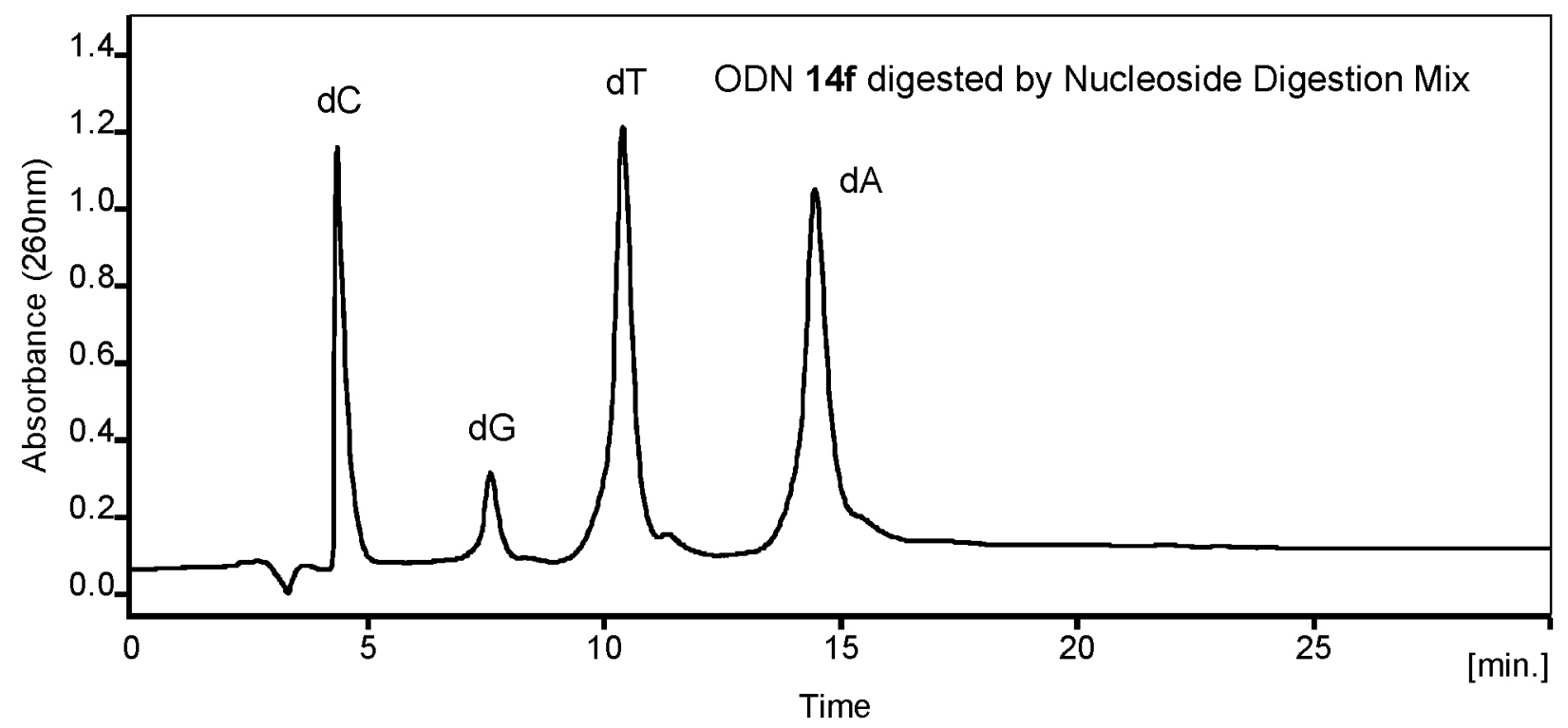

RP HPLC of nucleosides from enzyme digestion of the ODN $14 f$ 


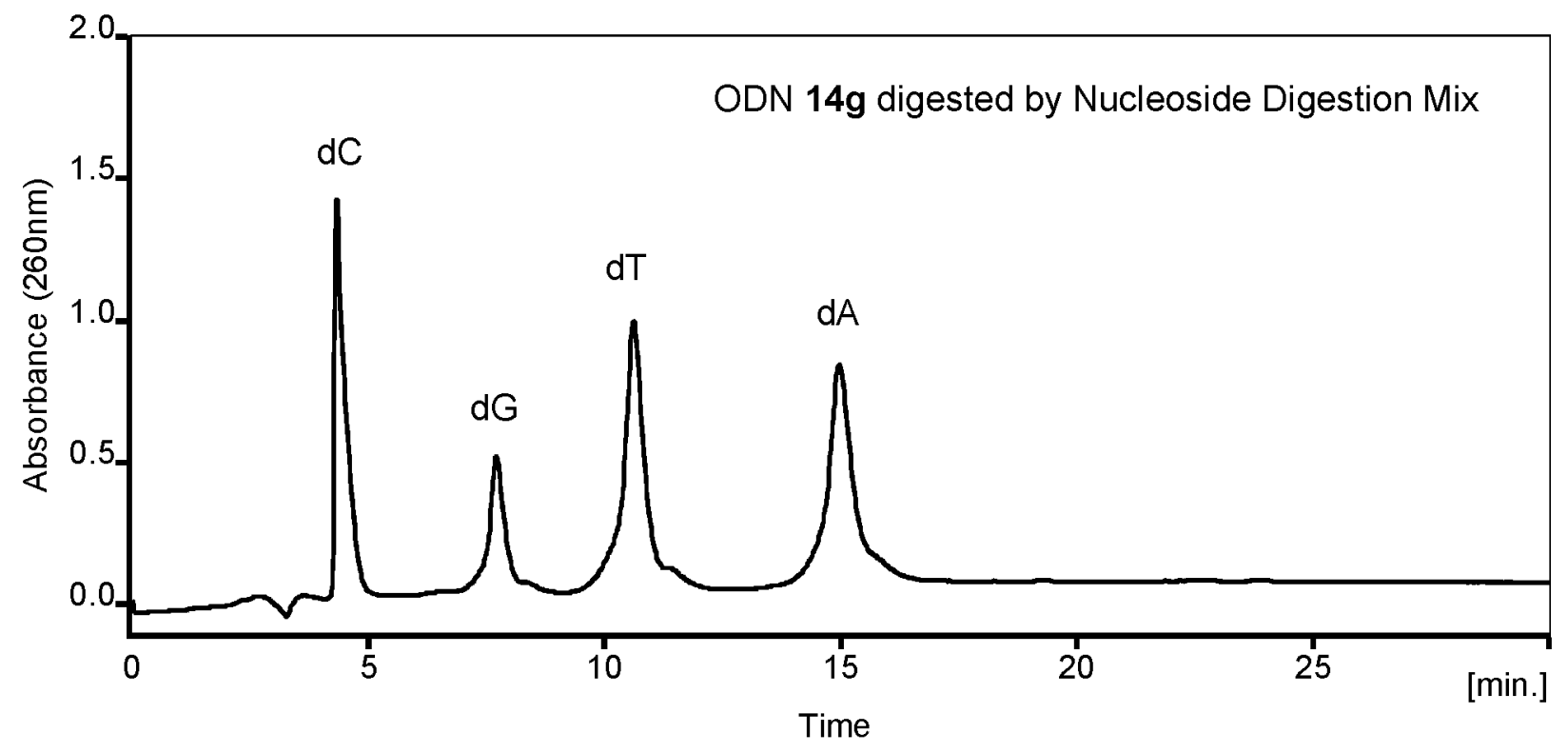

RP HPLC of nucleosides from enzyme digestion of the ODN $14 \mathrm{~g}$ 


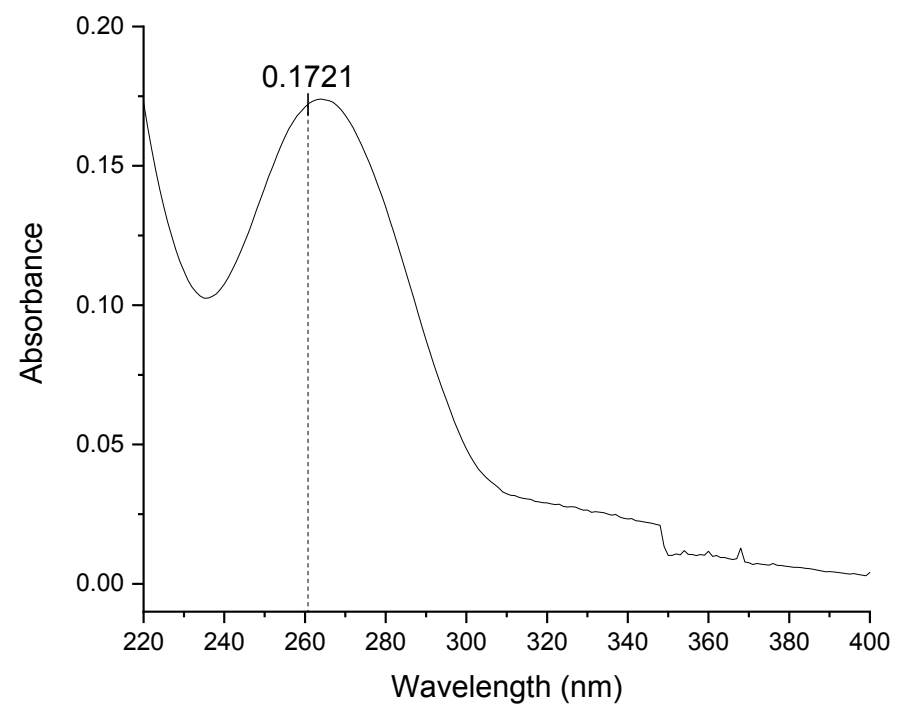

UV of ODN 14a: CPG (8, loading $26 \mu \mathrm{mol} / \mathrm{g}, 20 \mathrm{mg}$ ) of $0.52 \mu \mathrm{mol}$ synthesis was divided into 5 portions. One portion was deprotected and cleaved under non-nucleophilic conditions as described in the experimental section. After HPLC purification, the ODN was dissolved in $2.5 \mathrm{~mL}$ water and the above UV spectrum was measured. Thus, the $\mathrm{OD}_{260}$ of the ODN obtained from the $0.52 \mu \mathrm{mol}$ synthesis is $2.15(0.172 \times 12.5)$.

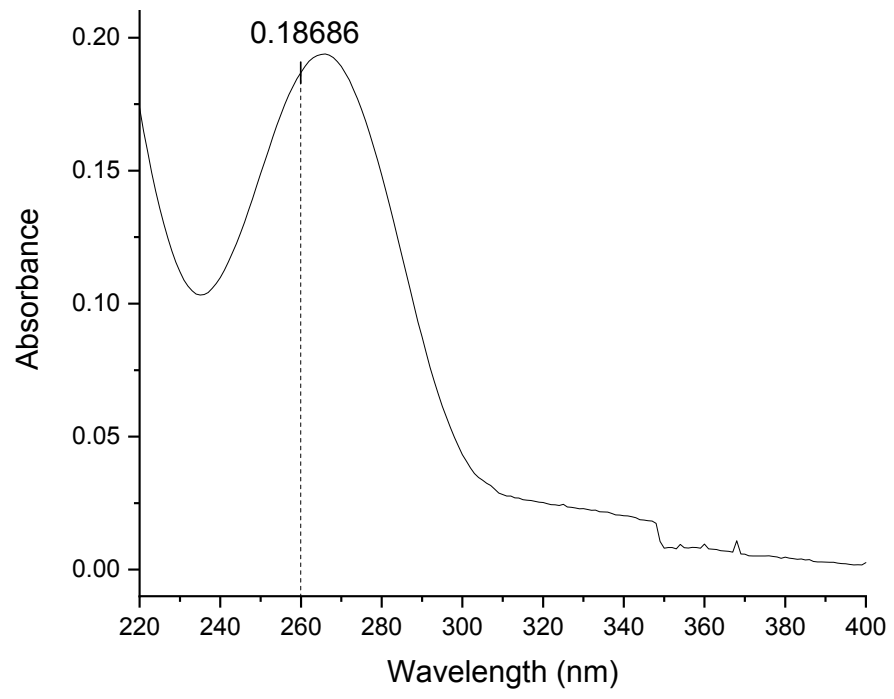

UV of ODN 14b: CPG (8, loading $26 \mu \mathrm{mol} / \mathrm{g}, 20 \mathrm{mg}$ ) of $0.52 \mu \mathrm{mol}$ synthesis was divided into 5 portions. One portion was deprotected and cleaved under non-nucleophilic conditions as described in the experimental section. After HPLC purification, the ODN was dissolved in $2.5 \mathrm{~mL}$ water and the above UV spectrum was measured. Thus, the $\mathrm{OD}_{260}$ of the ODN obtained from the $0.52 \mu \mathrm{mol}$ synthesis is $2.34(0.187 \times 12.5)$. 


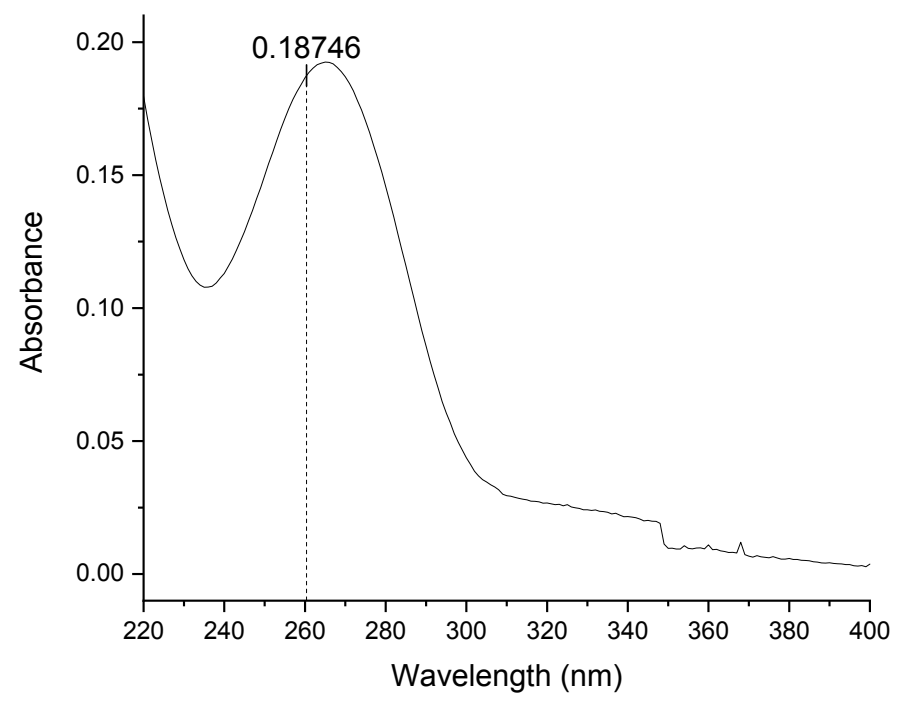

UV of ODN 14c: CPG (8, loading $26 \mu \mathrm{mol} / \mathrm{g}, 20 \mathrm{mg}$ ) of $0.52 \mu \mathrm{mol}$ synthesis was divided into 5 portions. One portion was deprotected and cleaved under non-nucleophilic conditions as described in the experimental section. After HPLC purification, the ODN was dissolved in $2.5 \mathrm{~mL}$ water and the above UV spectrum was measured. Thus, the $\mathrm{OD}_{260}$ of the ODN obtained from the $0.52 \mu \mathrm{mol}$ synthesis is $2.34(0.187 \times 12.5)$.

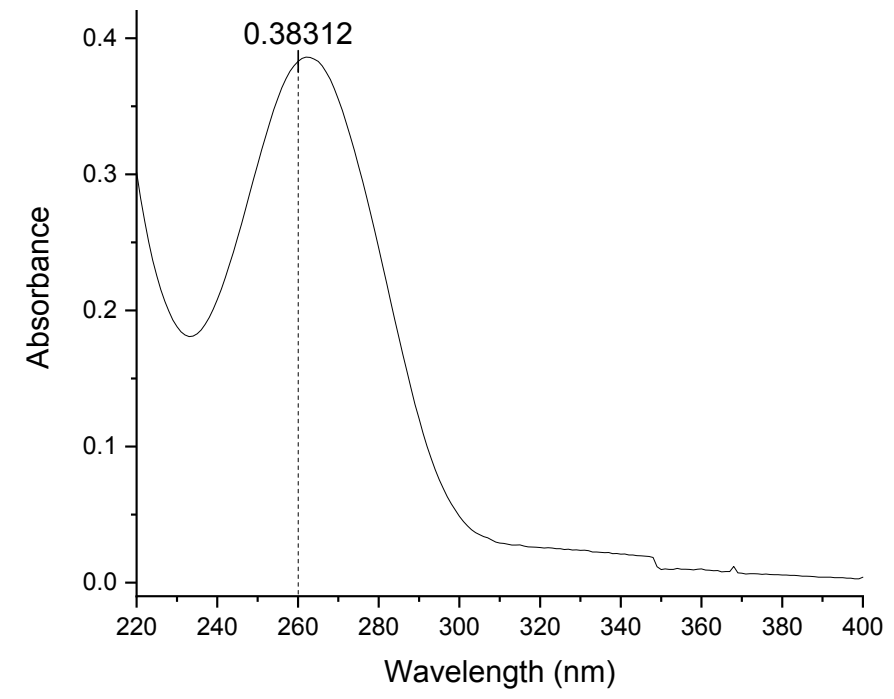

UV of ODN 14d: CPG (8, loading $26 \mu \mathrm{mol} / \mathrm{g}, 20 \mathrm{mg}$ ) of $0.52 \mu \mathrm{mol}$ synthesis was divided into 5 portions. One portion was deprotected and cleaved under non-nucleophilic conditions as described in the experimental section. After HPLC purification, the ODN was dissolved in $2.5 \mathrm{~mL}$ water and the above UV spectrum was measured. Thus, the $\mathrm{OD}_{260}$ of the ODN obtained from the $0.52 \mu \mathrm{mol}$ synthesis is $4.79(0.383 \times 12.5)$. 


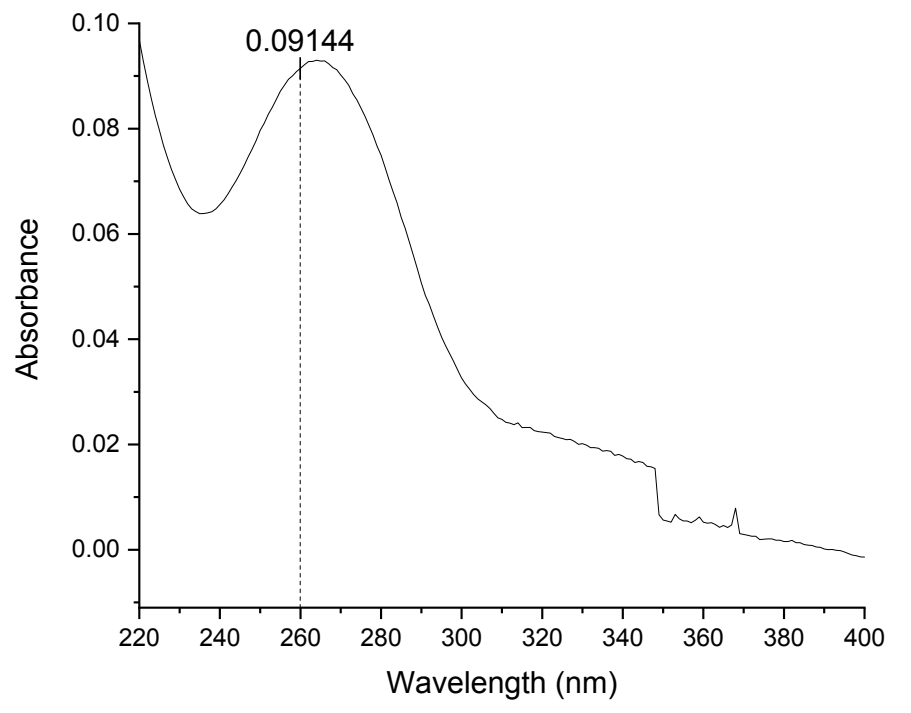

UV of ODN 14e: CPG (8, loading $26 \mu \mathrm{mol} / \mathrm{g}, 20 \mathrm{mg}$ ) of $0.52 \mu \mathrm{mol}$ synthesis was divided into 5 portions. One portion was deprotected and cleaved under non-nucleophilic conditions as described in the experimental section. After HPLC purification, the ODN was dissolved in $2.5 \mathrm{~mL}$ water and the above UV spectrum was measured. Thus, the $\mathrm{OD}_{260}$ of the ODN obtained from the $0.52 \mu \mathrm{mol}$ synthesis is $1.14(0.091 \times 12.5)$.

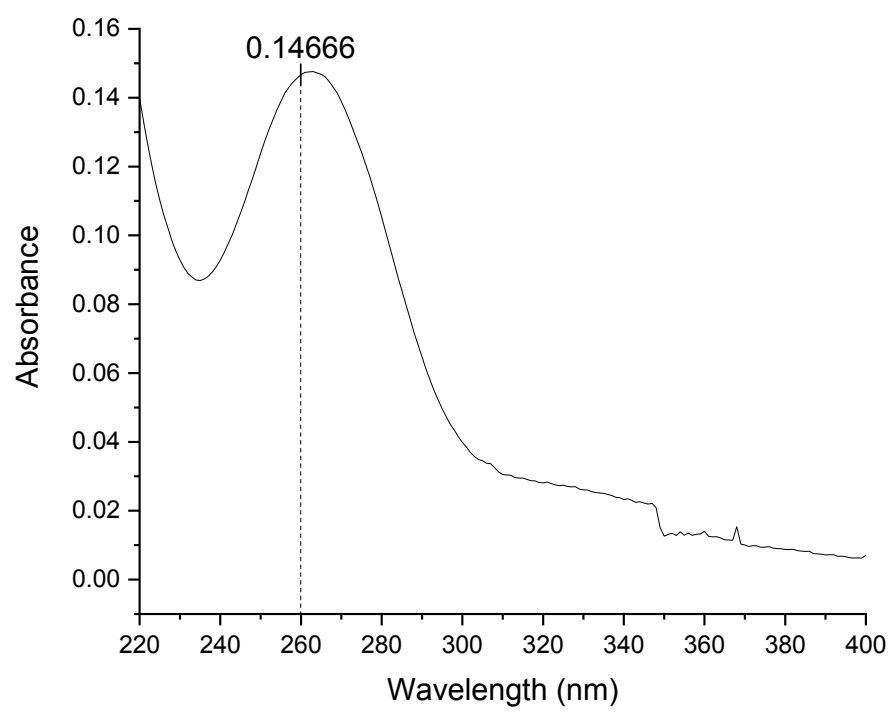

UV of ODN 14f: CPG (8, loading $26 \mu \mathrm{mol} / \mathrm{g}, 20 \mathrm{mg}$ ) of $0.52 \mu \mathrm{mol}$ synthesis was divided into 5 portions. One portion was deprotected and cleaved under non-nucleophilic conditions as described in the experimental section. After HPLC purification, the ODN was dissolved in $2.5 \mathrm{~mL}$ water and the above UV spectrum was measured. Thus, the $\mathrm{OD}_{260}$ of the ODN obtained from the $0.52 \mu \mathrm{mol}$ synthesis is $1.84(0.147 \times 12.5)$. 


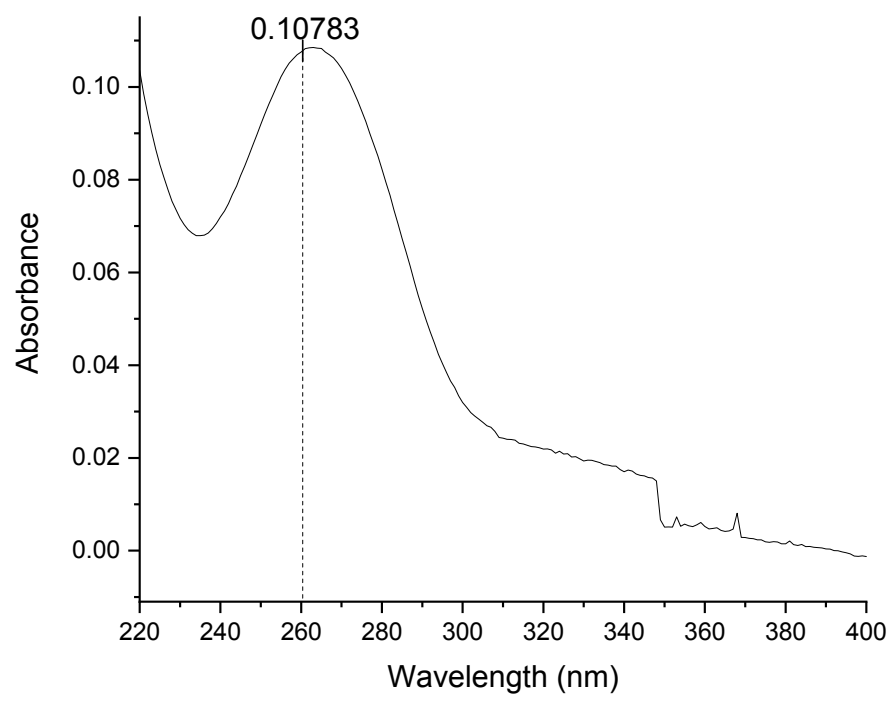

UV of ODN 14g: CPG (8, loading $26 \mu \mathrm{mol} / \mathrm{g}, 20 \mathrm{mg}$ ) of $0.52 \mu \mathrm{mol}$ synthesis was divided into 5 portions. One portion was deprotected and cleaved under non-nucleophilic conditions as described in the experimental section. After HPLC purification, the ODN was dissolved in $2.5 \mathrm{~mL}$ water and the above UV spectrum was measured. Thus, the $\mathrm{OD}_{260}$ of the ODN obtained from the $0.52 \mu \mathrm{mol}$ synthesis is $1.35(0.108 \times 12.5)$. 

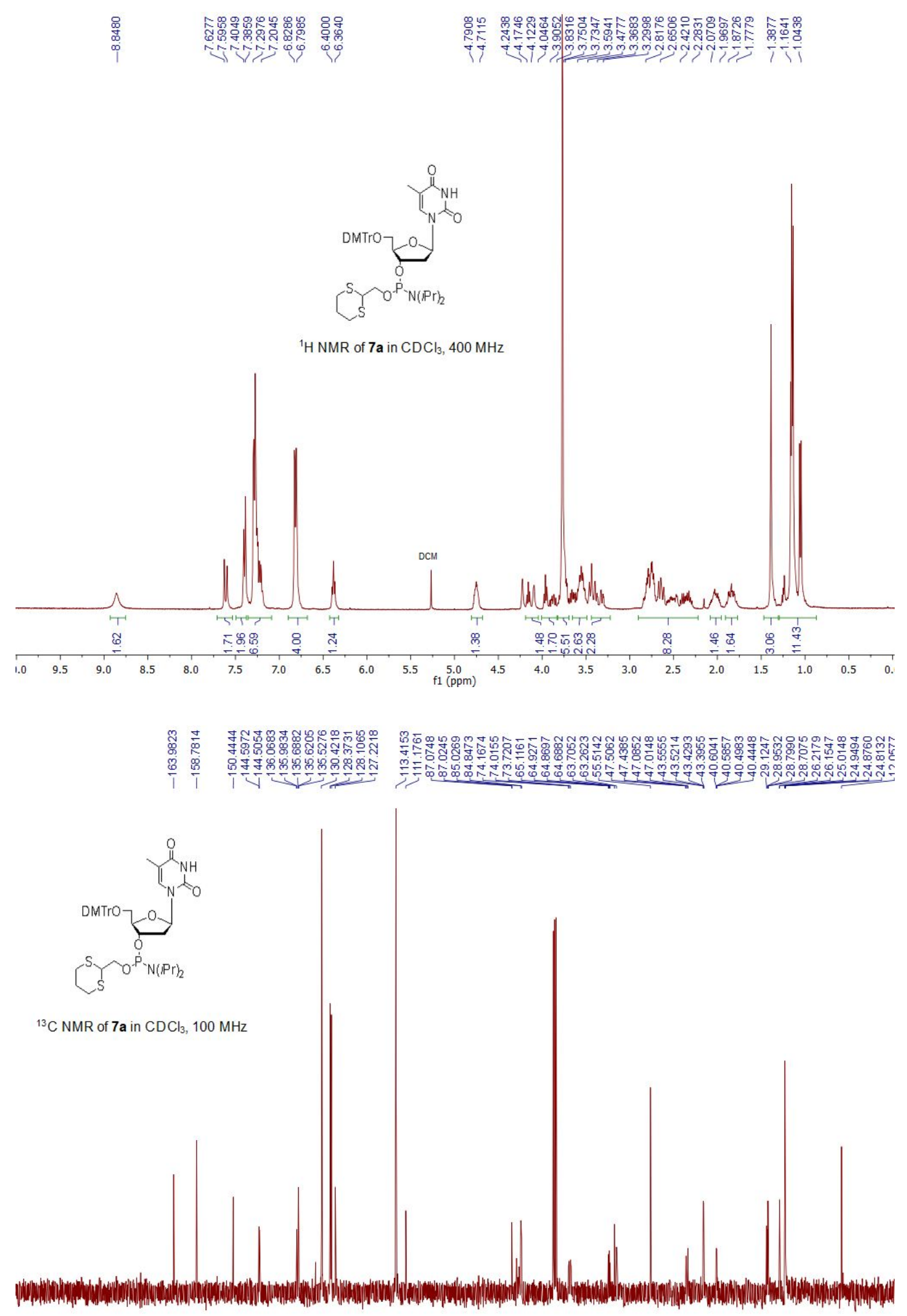

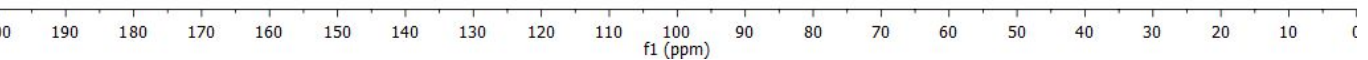




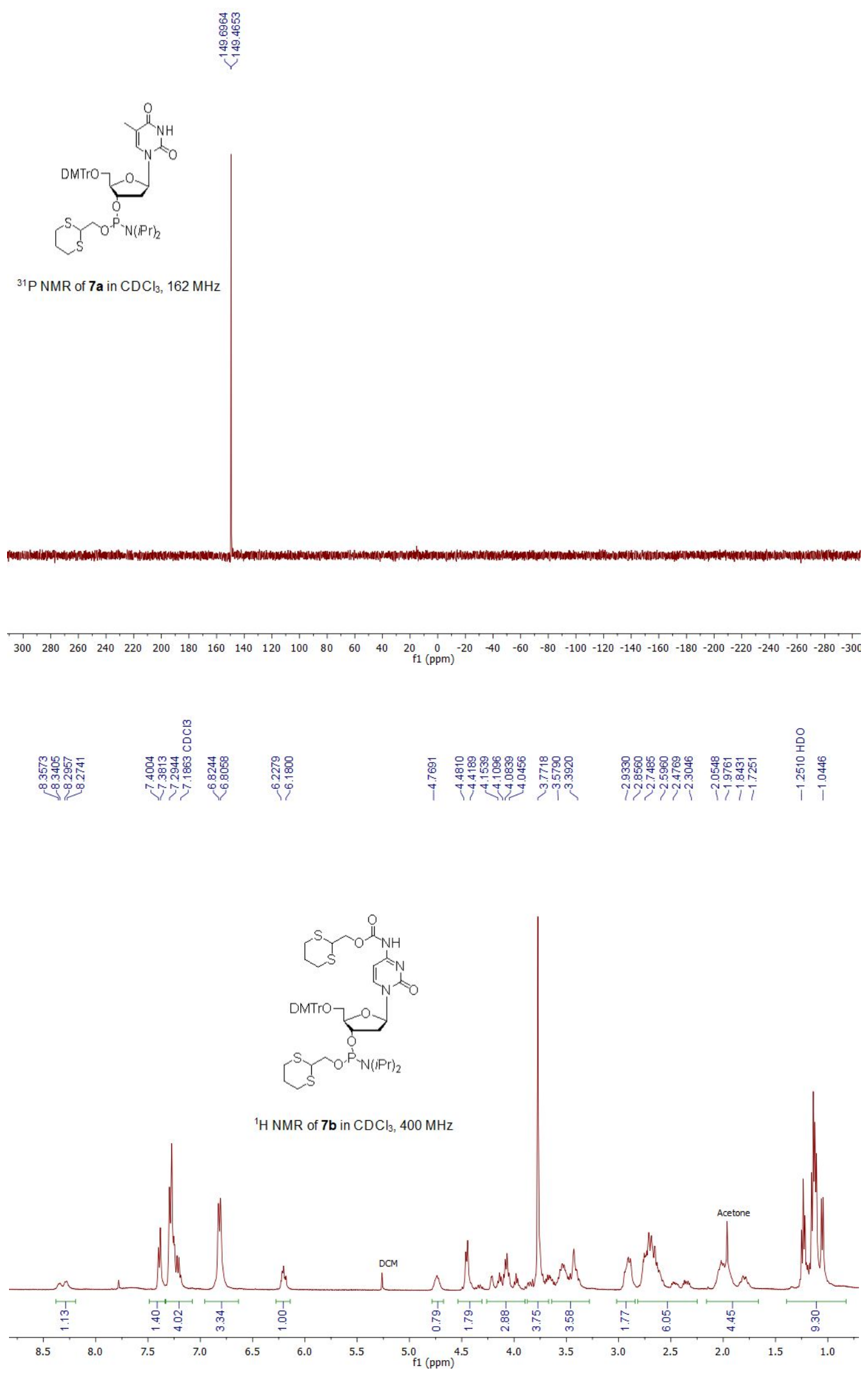




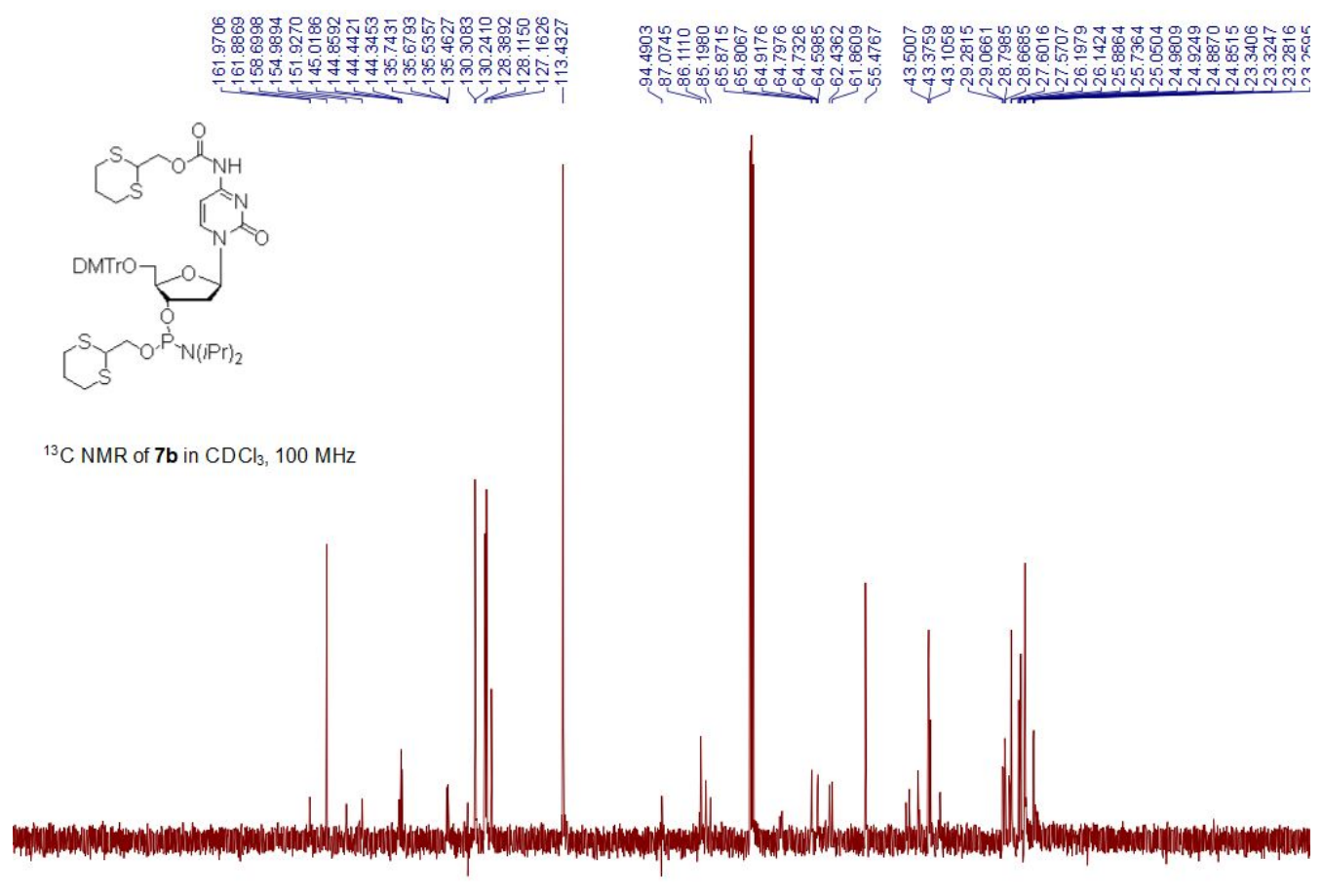

$\begin{array}{lllllllllllllllllllllllll}210 & 200 & 190 & 180 & 170 & 160 & 150 & 140 & 130 & 120 & 110 & 100 & 90 & 80 & 70 & 60 & 50 & 40 & 30 & 20 & 10 & 0 & -10 & -20 & \end{array}$

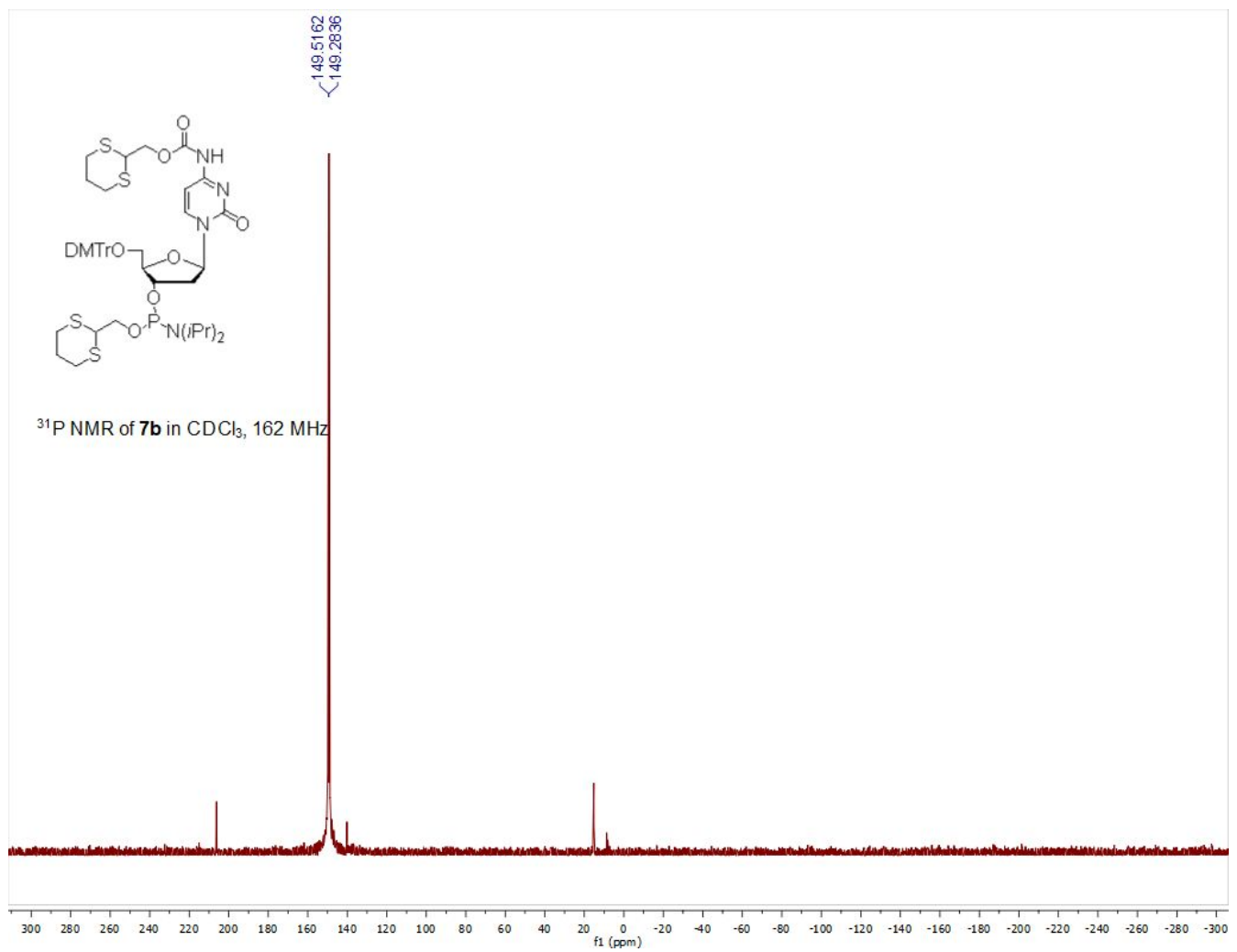



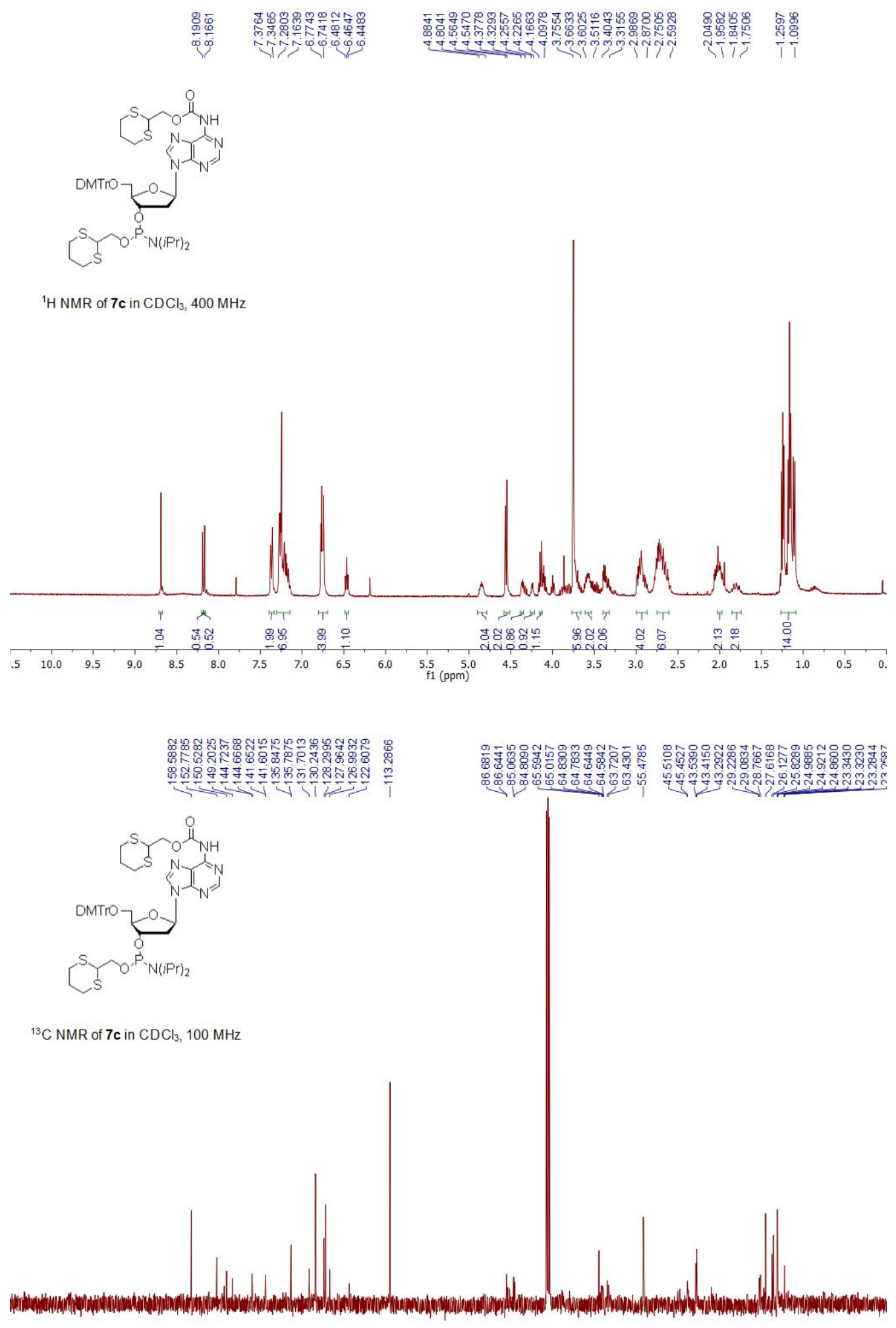

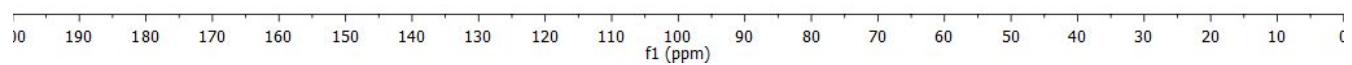




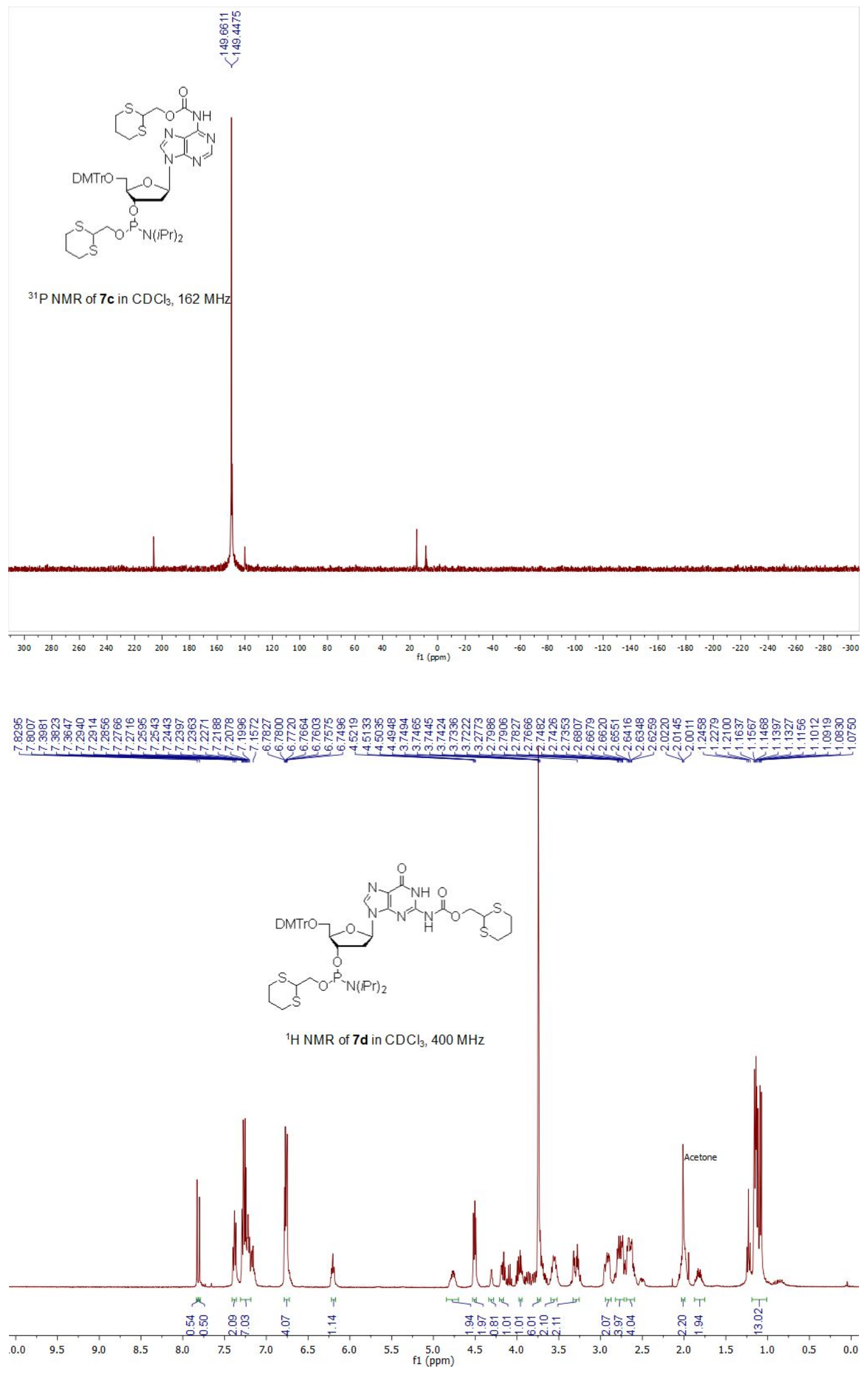



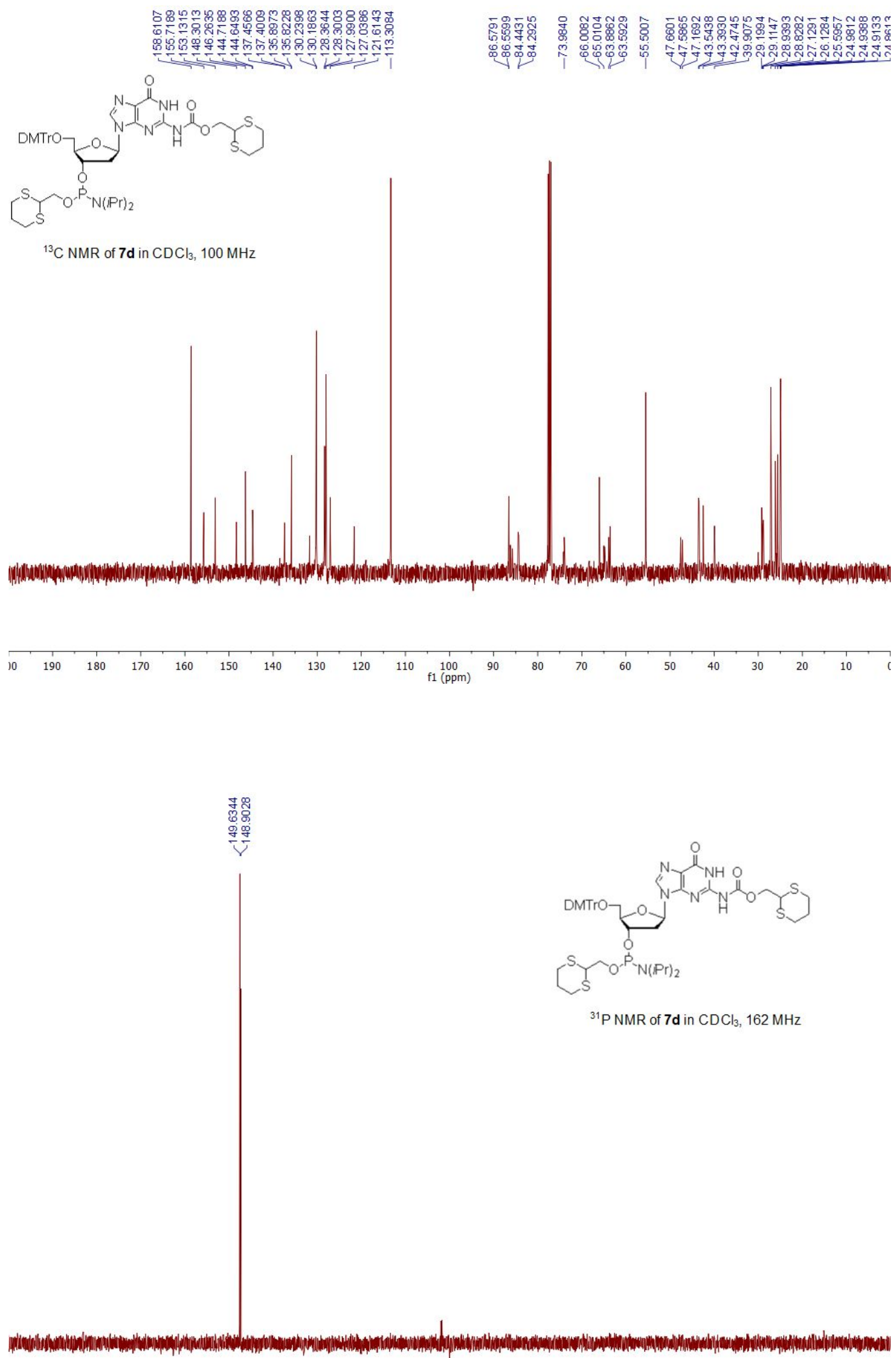

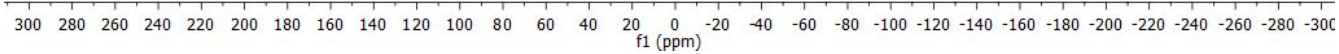



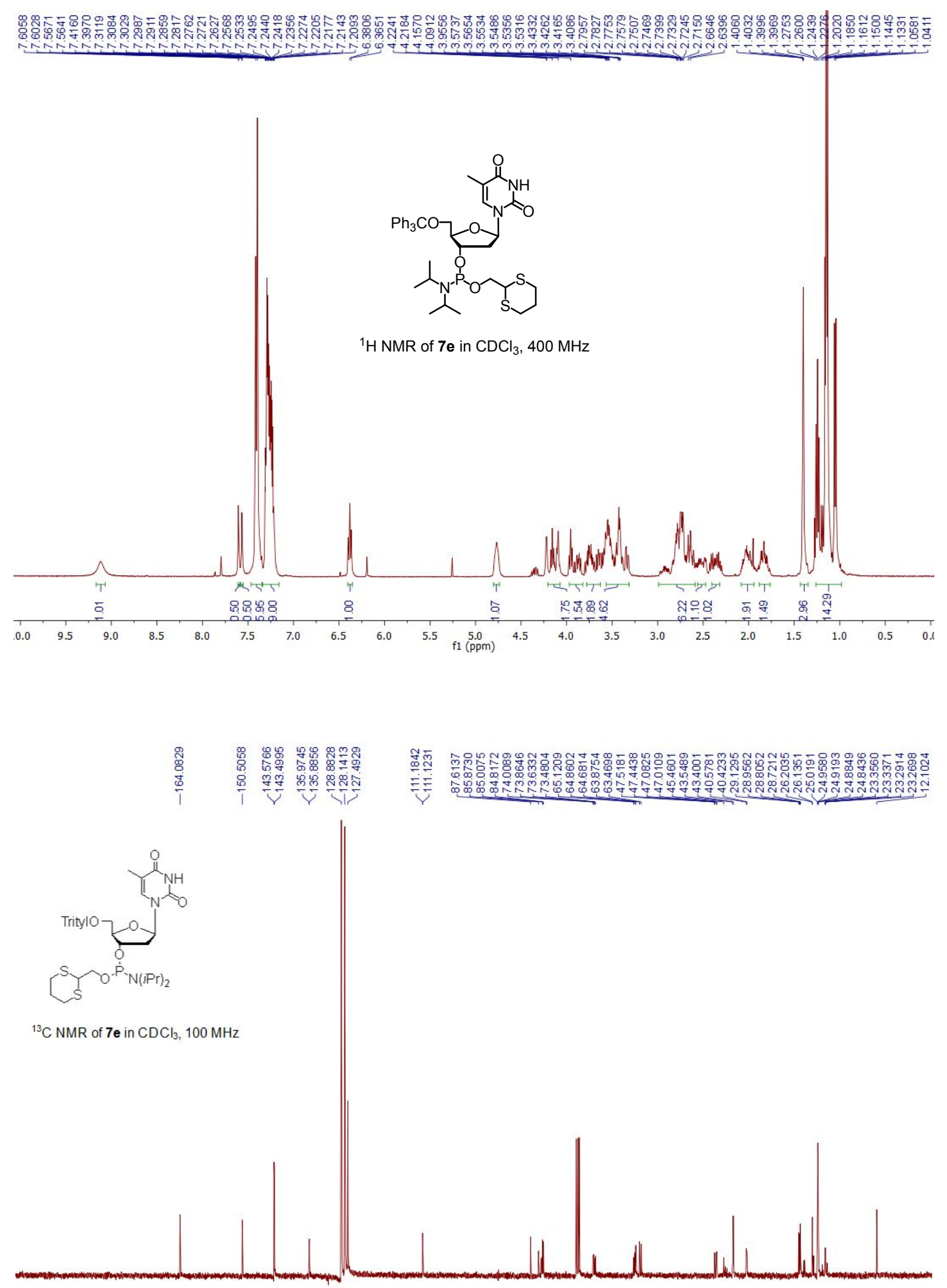

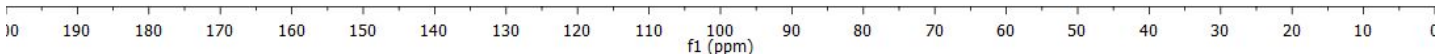




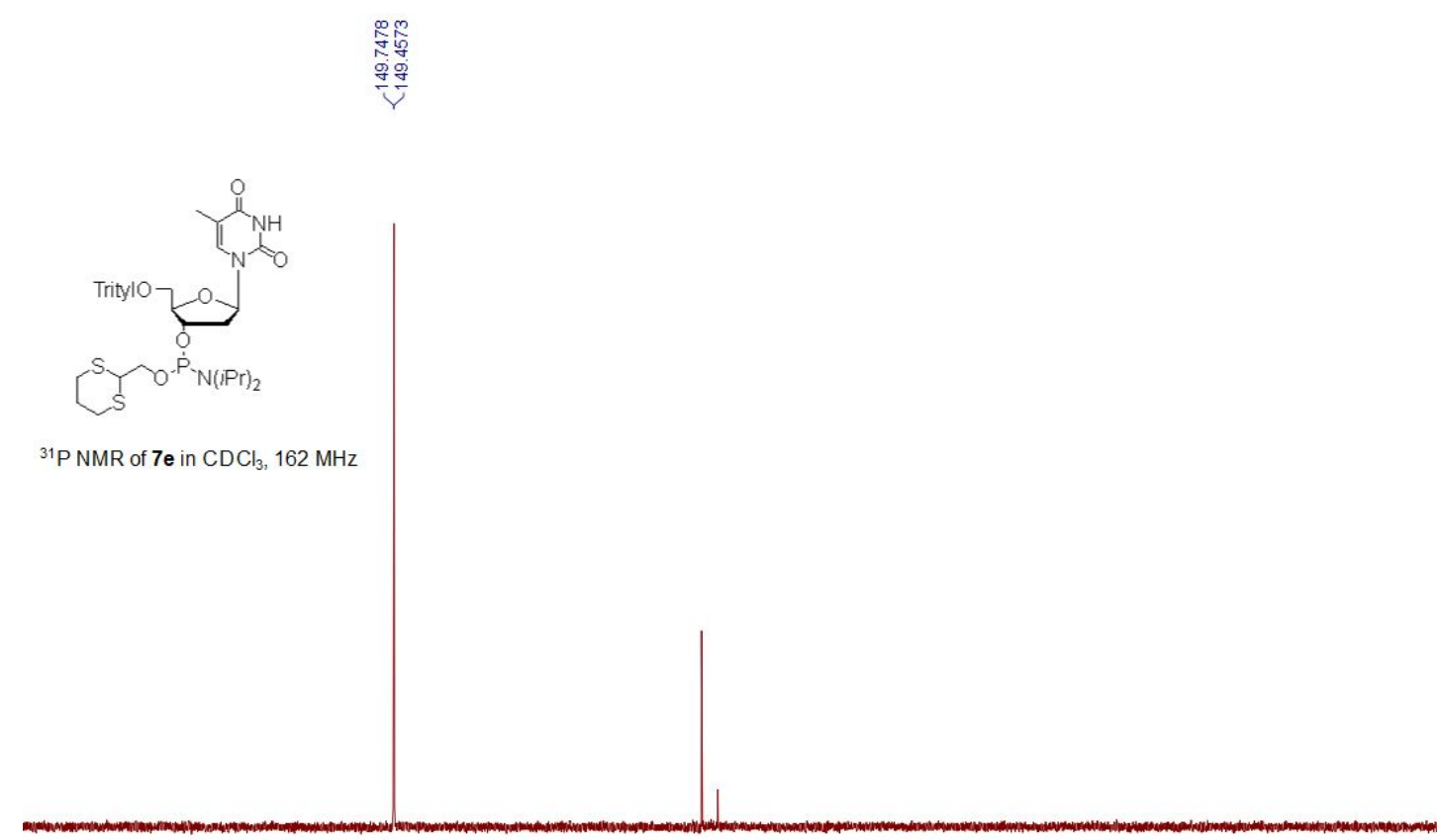

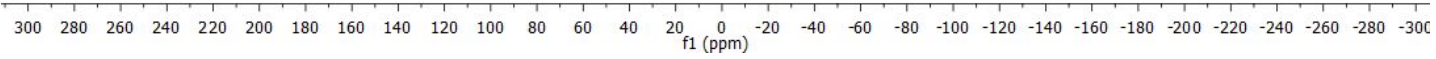
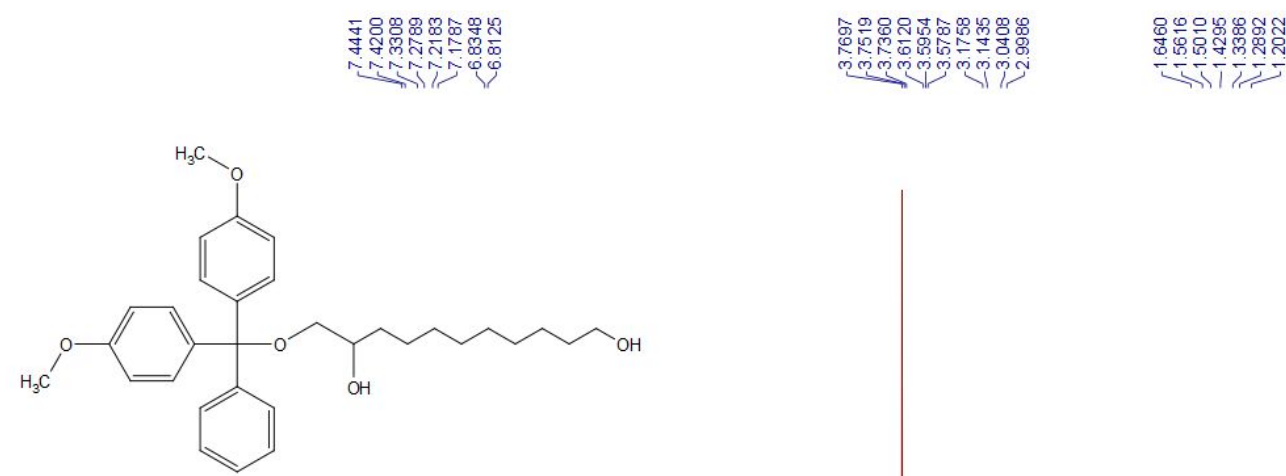

${ }^{1} \mathrm{H}$ NMR of 20 in $\mathrm{CDCl}_{3}, 400 \mathrm{MHz}$

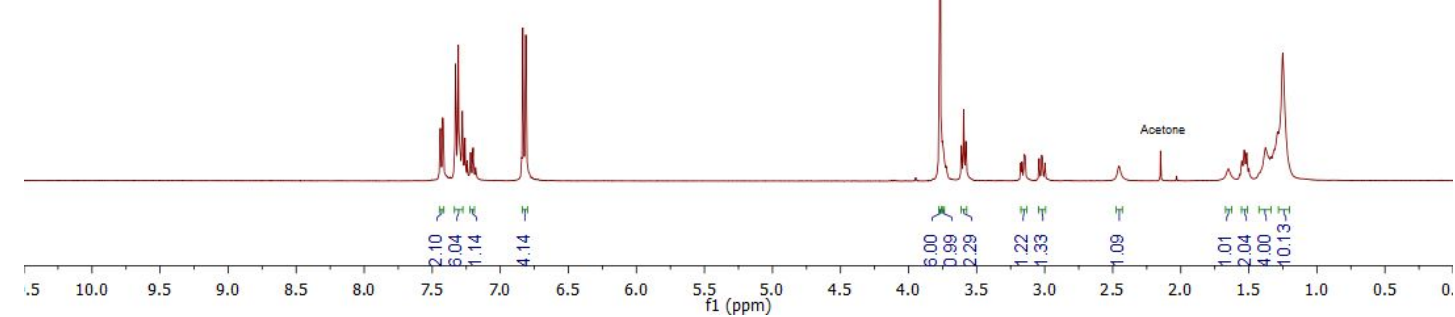



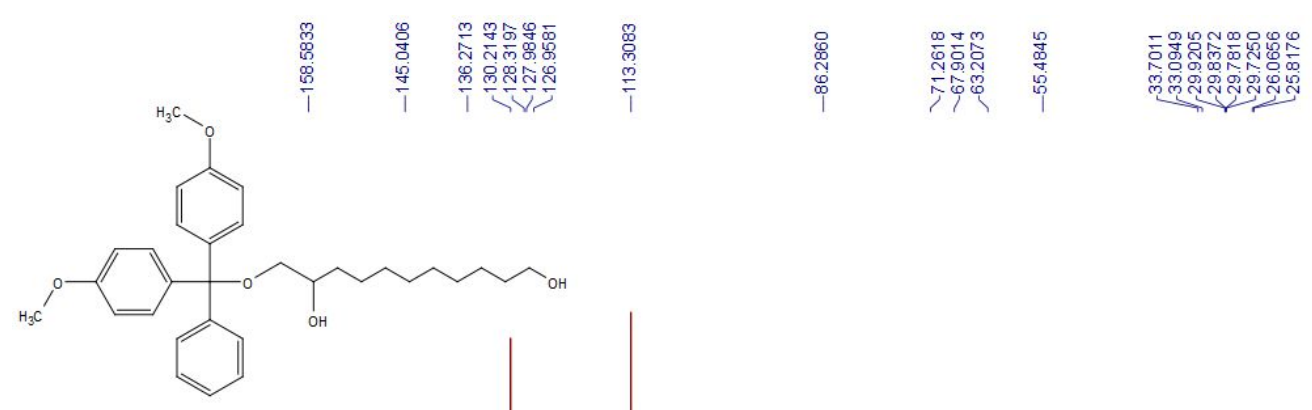

${ }^{13} \mathrm{C} \mathrm{NMR}$ of 20 in $\mathrm{CDCl}_{3}, 100 \mathrm{MHz}$
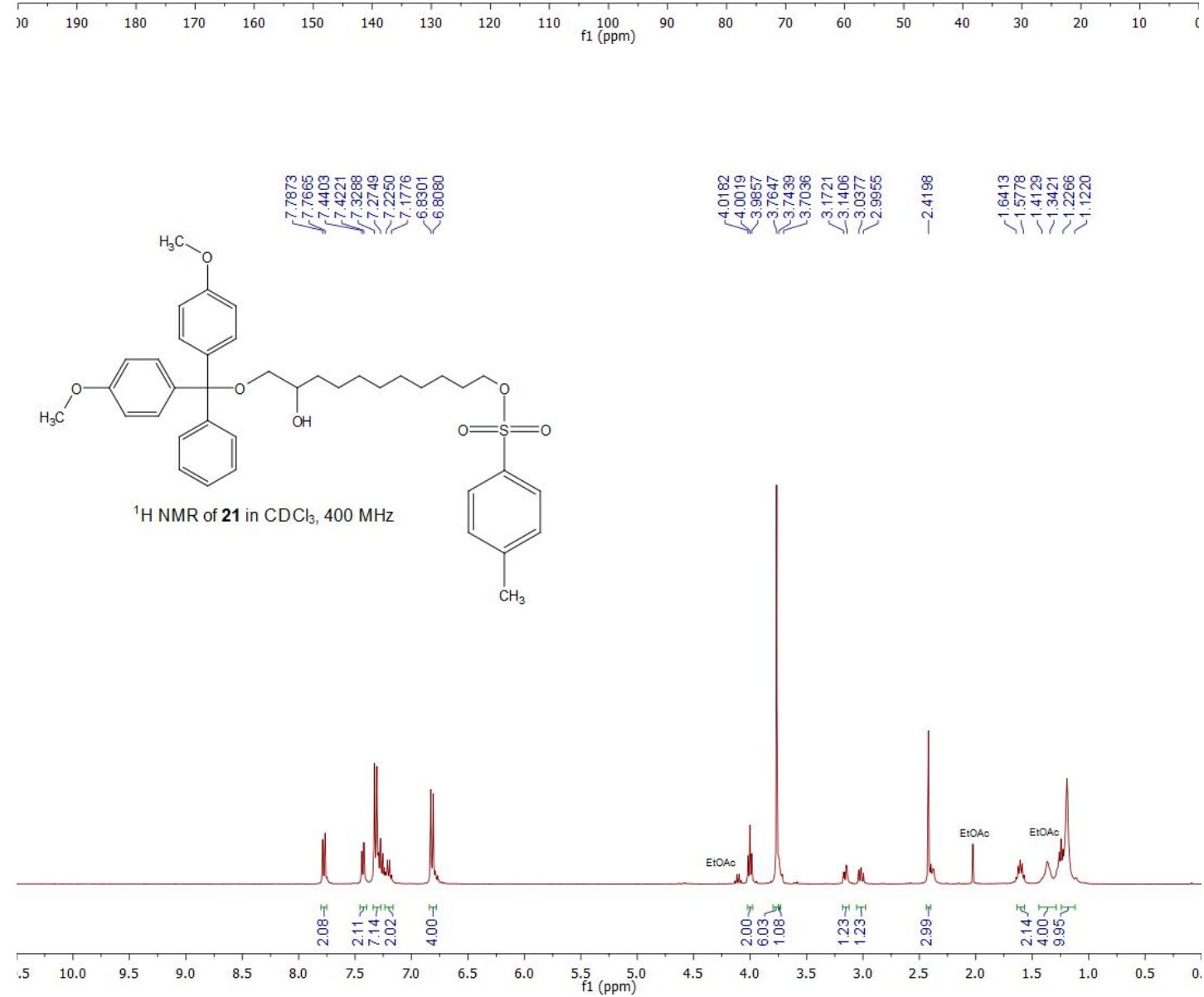

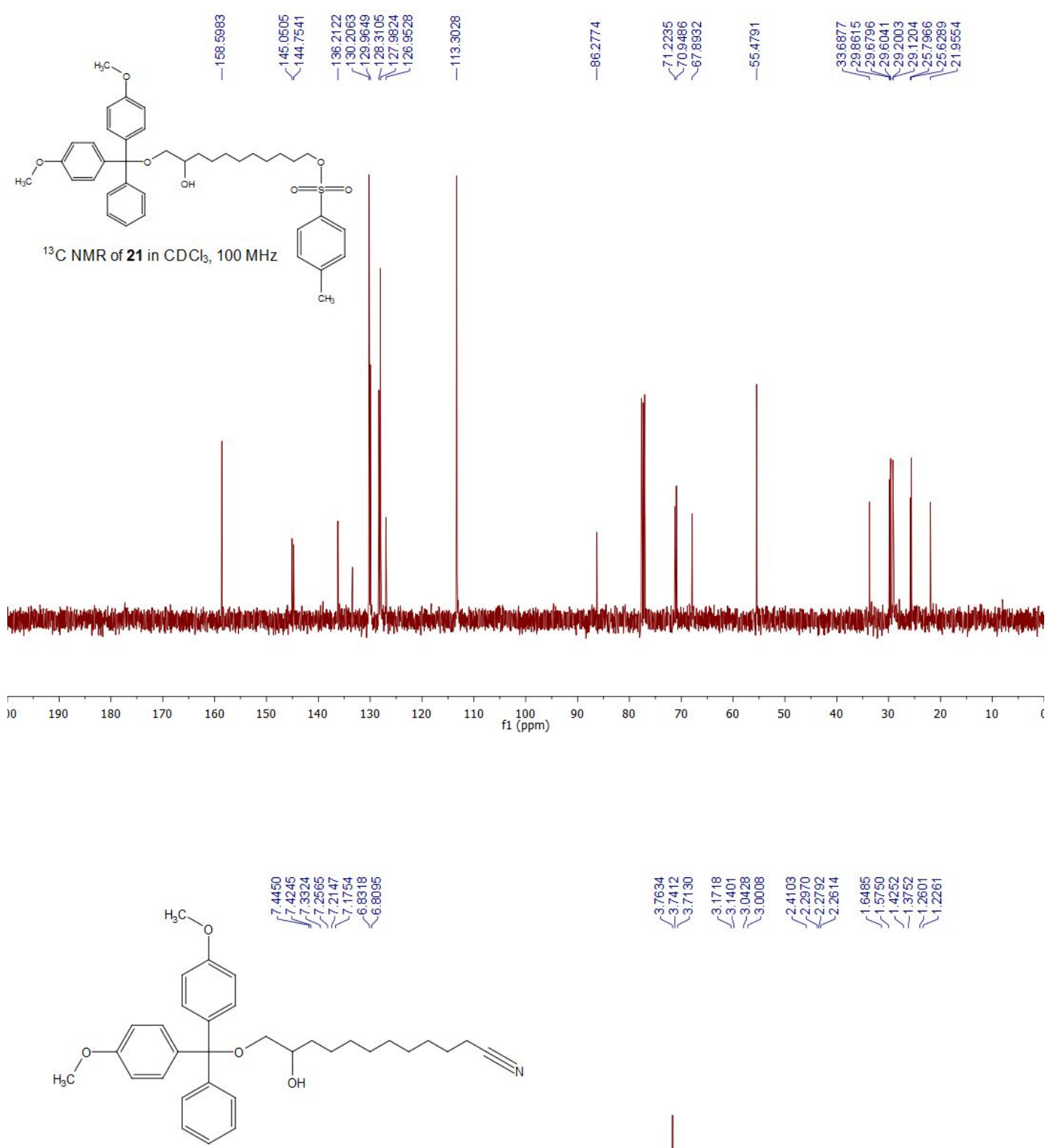

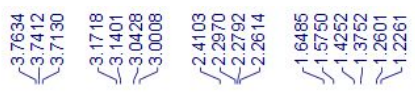

${ }^{1} \mathrm{H}$ NMR of 22 in $\mathrm{CDCl}_{3}, 400 \mathrm{MHz}$

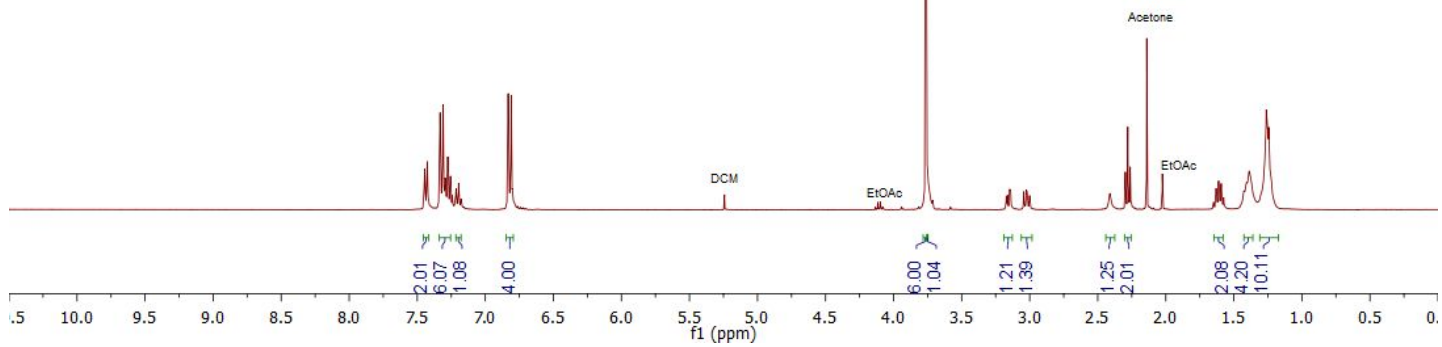



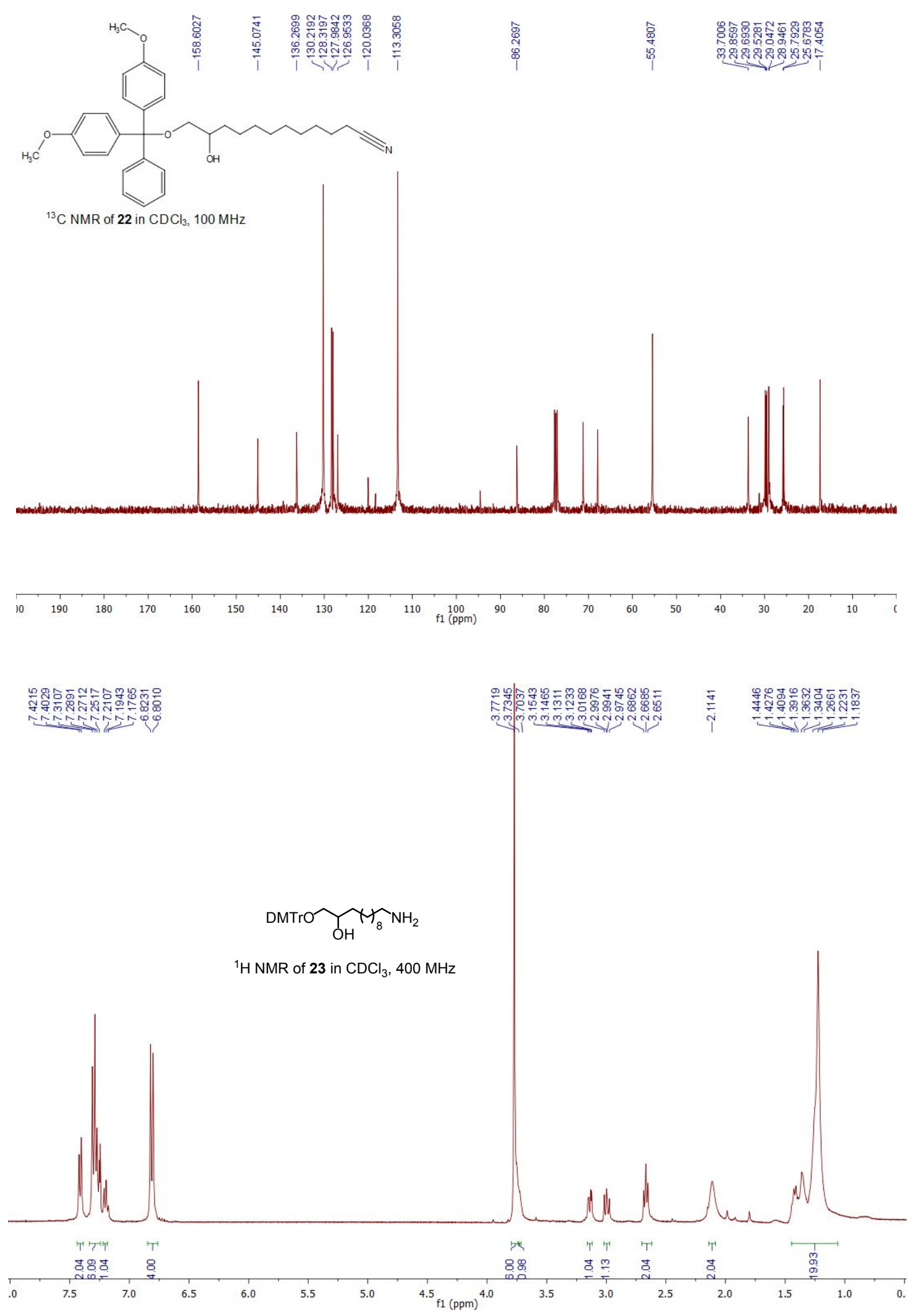

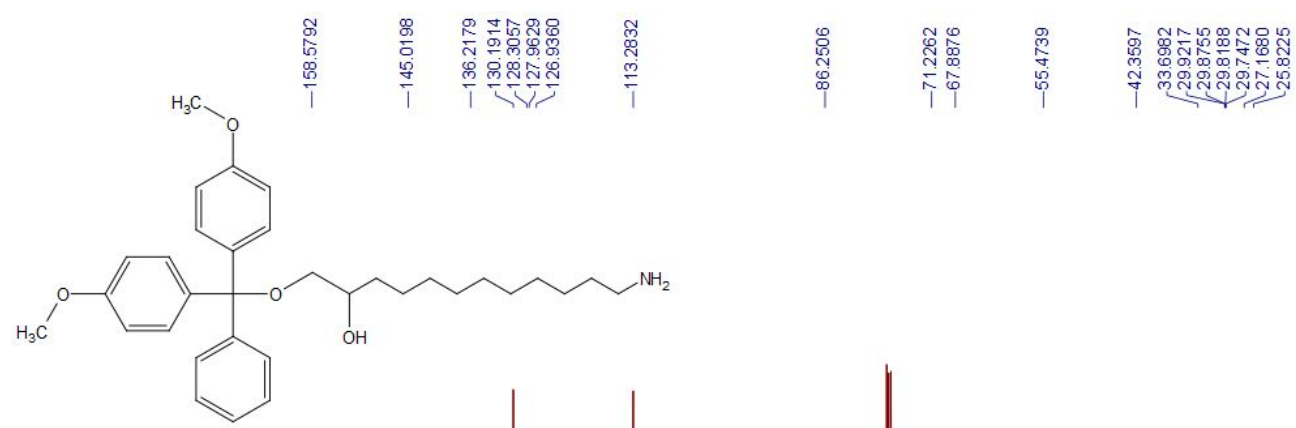

${ }^{13} \mathrm{C}$ NMR of 23 in $\mathrm{CDCl}_{3}, 100 \mathrm{MHz}$
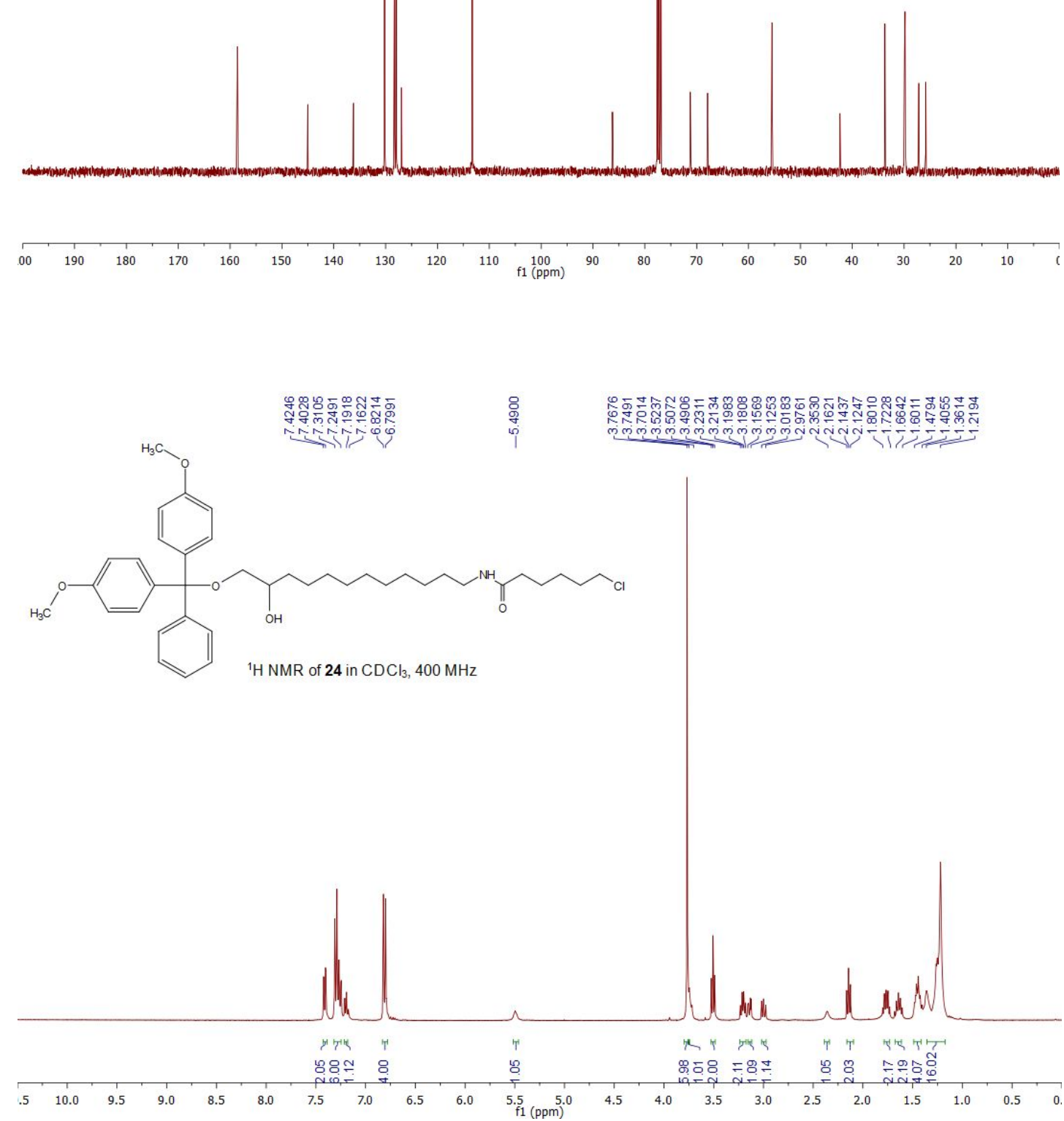

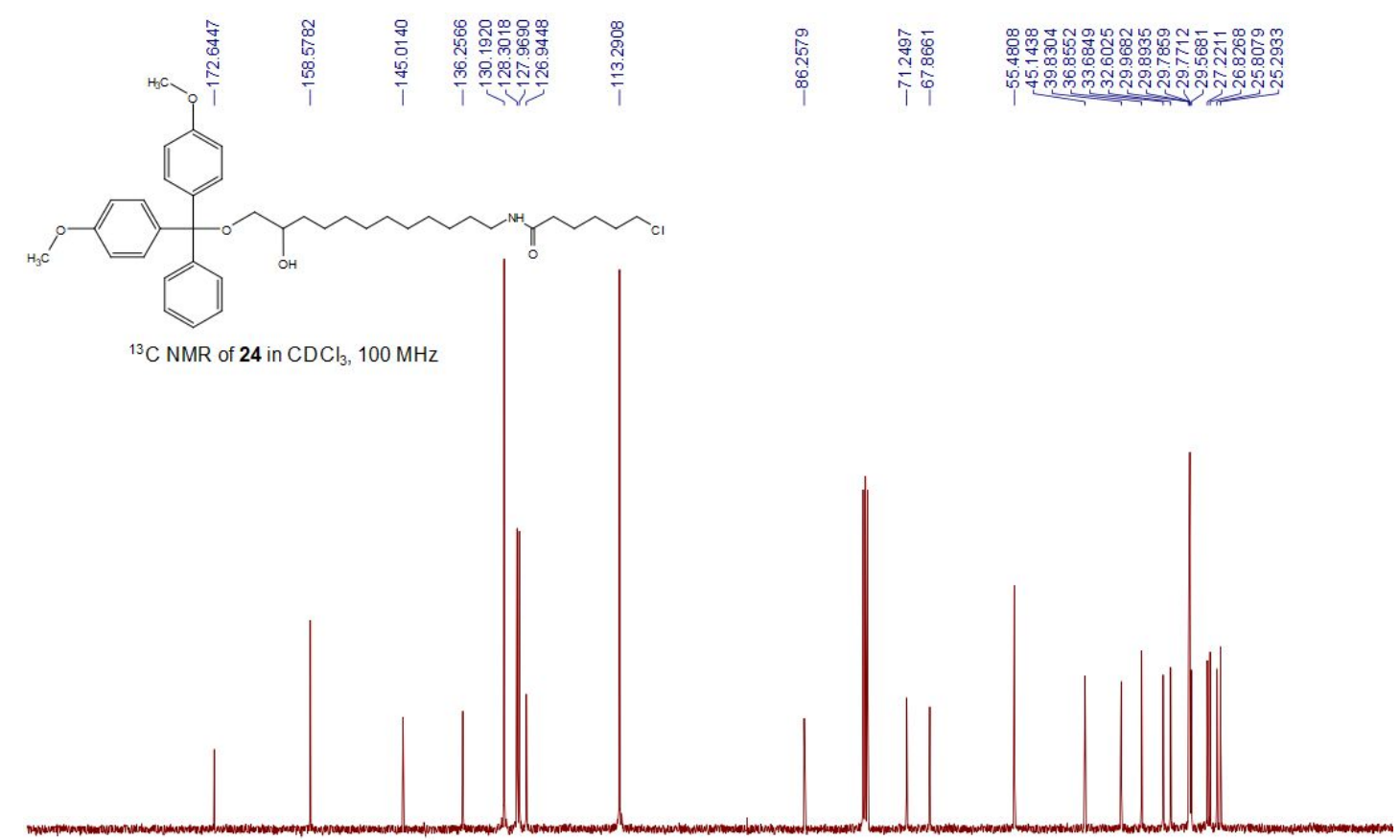

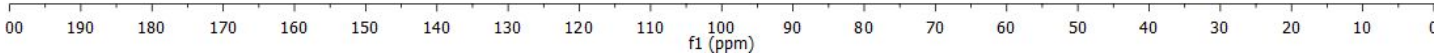
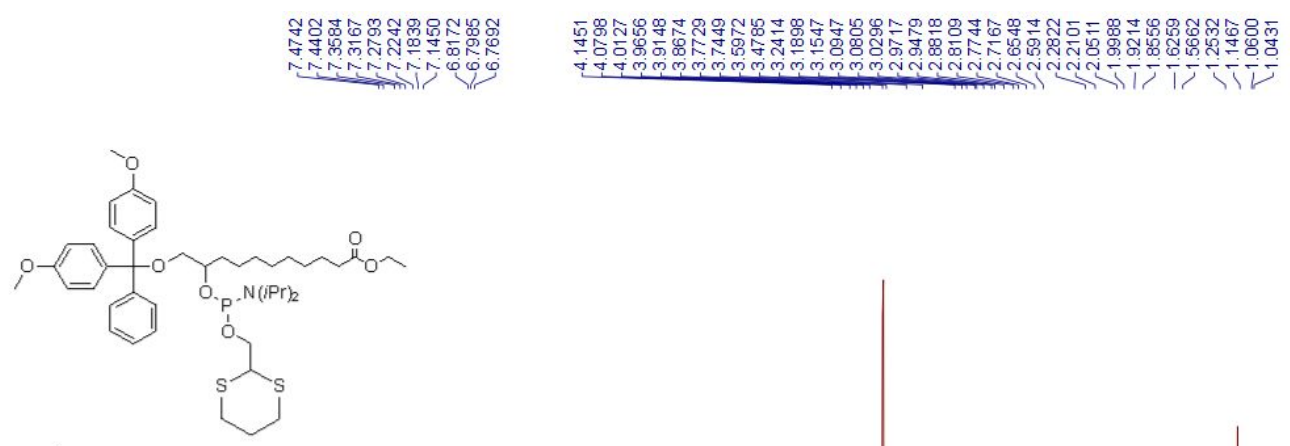

${ }^{1} \mathrm{H}$ NMR of $18 \mathrm{a}$ in $\mathrm{CDCl}_{3}, 400 \mathrm{MHz}$

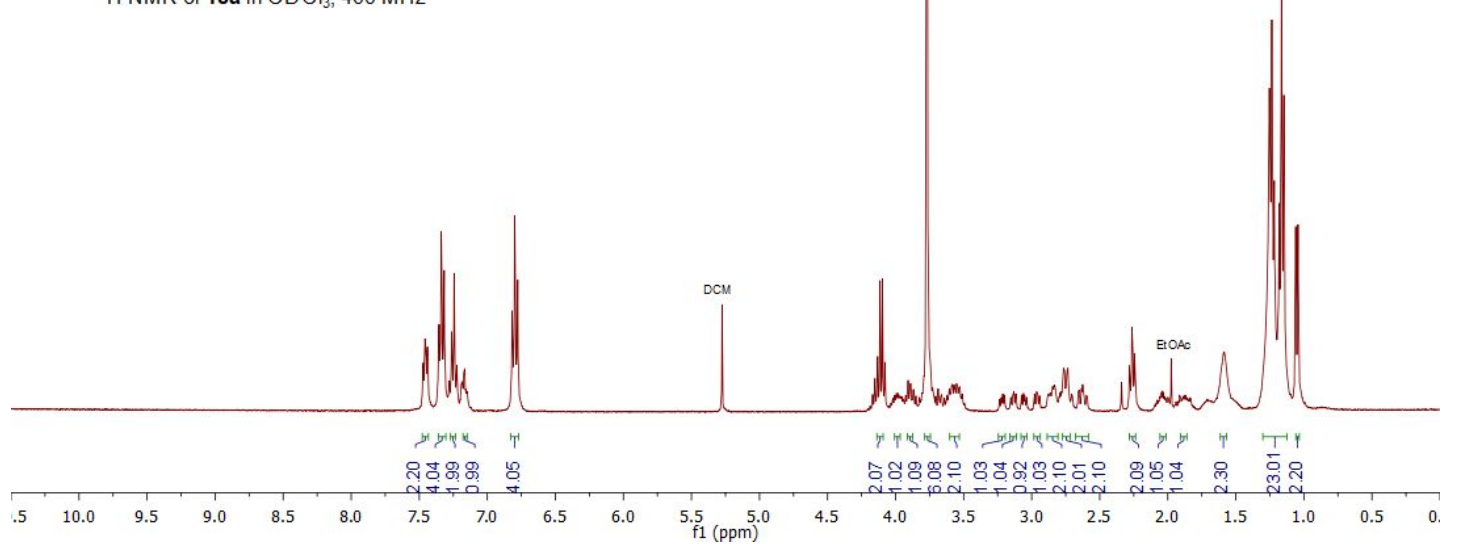



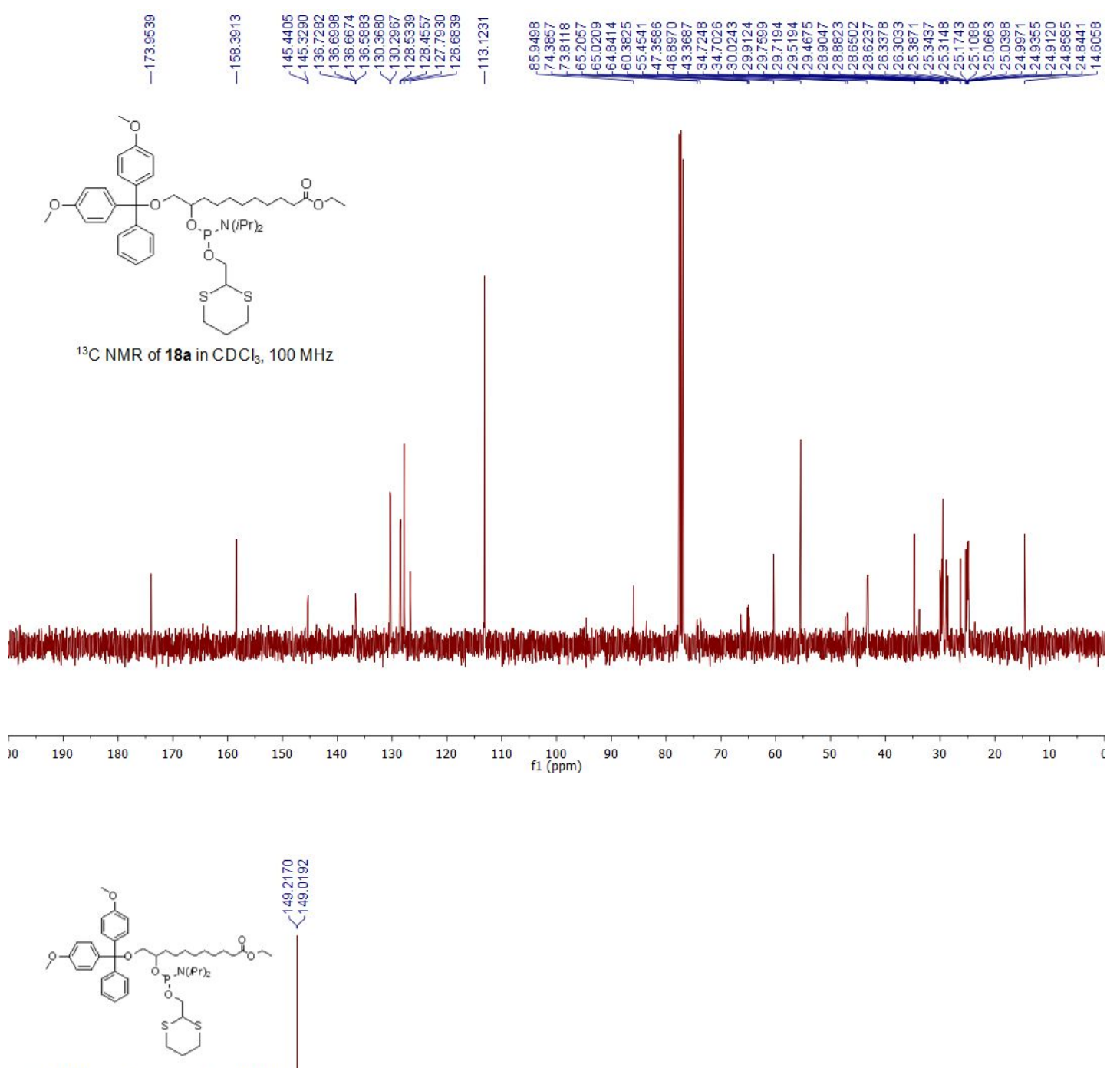

${ }^{31} \mathrm{P} \mathrm{NMR}$ of $18 \mathrm{a}$ in $\mathrm{CDCl}_{3}, 162 \mathrm{MHz}$

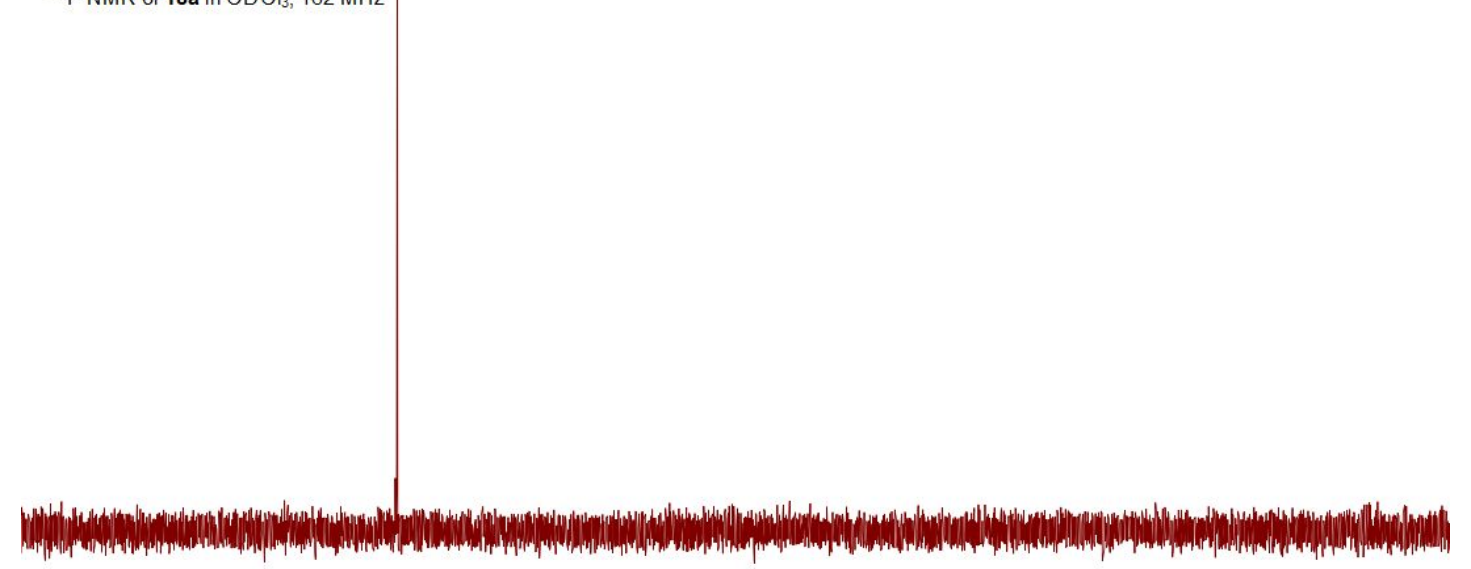

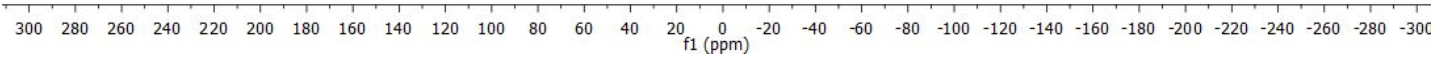



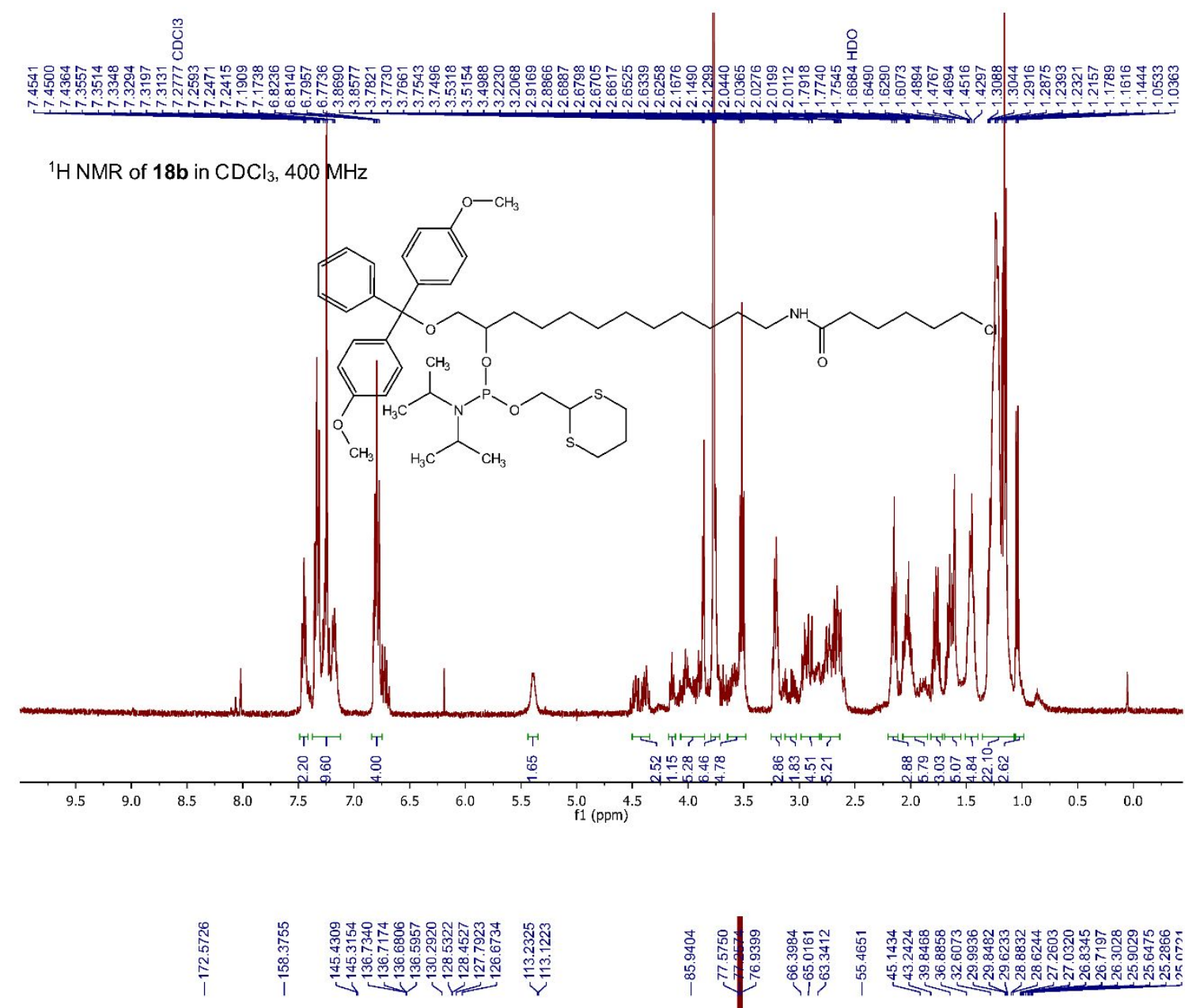

${ }^{13} \mathrm{C}$ NMR of $18 \mathbf{b}$ in $\mathrm{CDCl}_{3}, 100 \mathrm{MHz}$

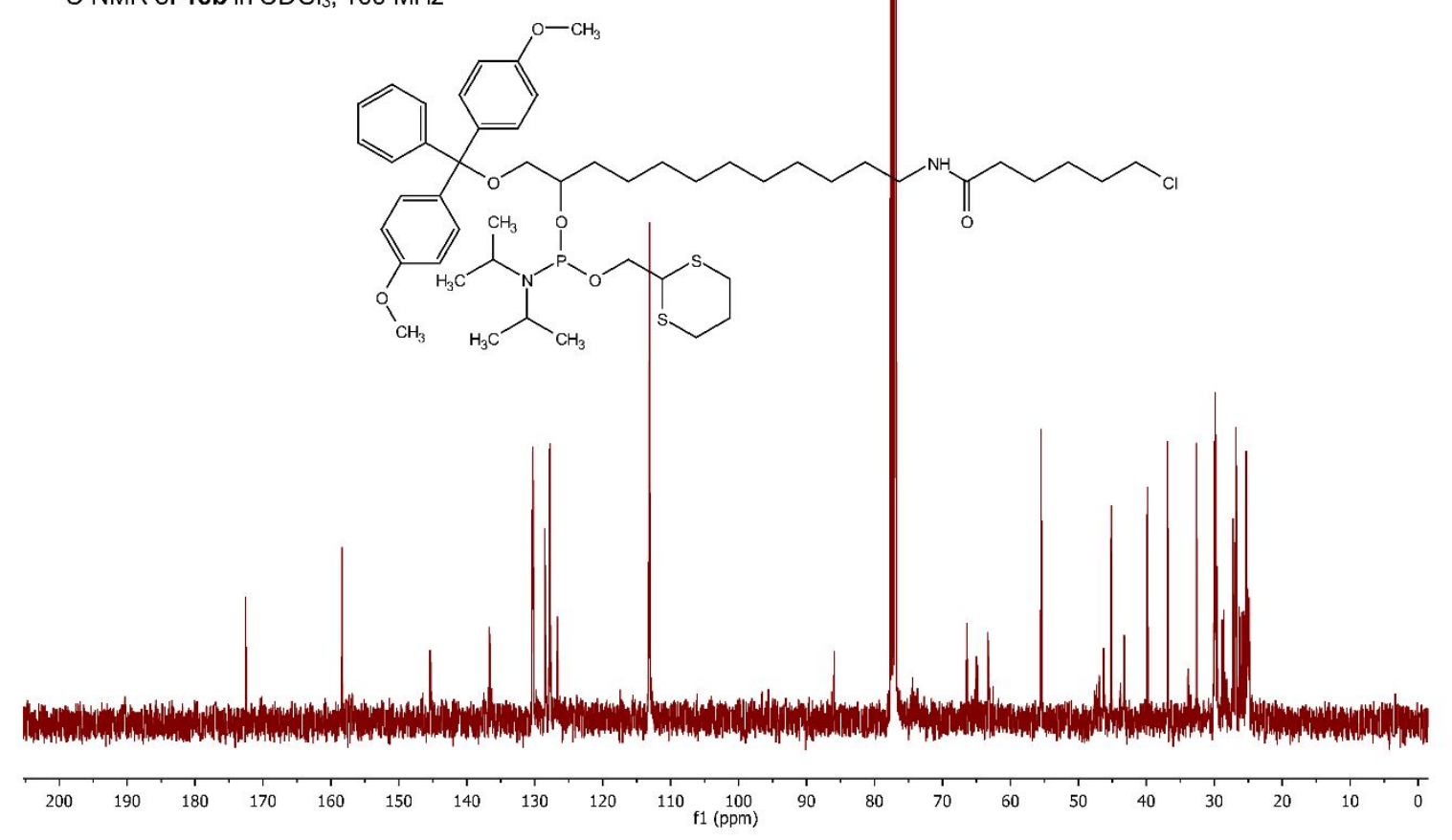




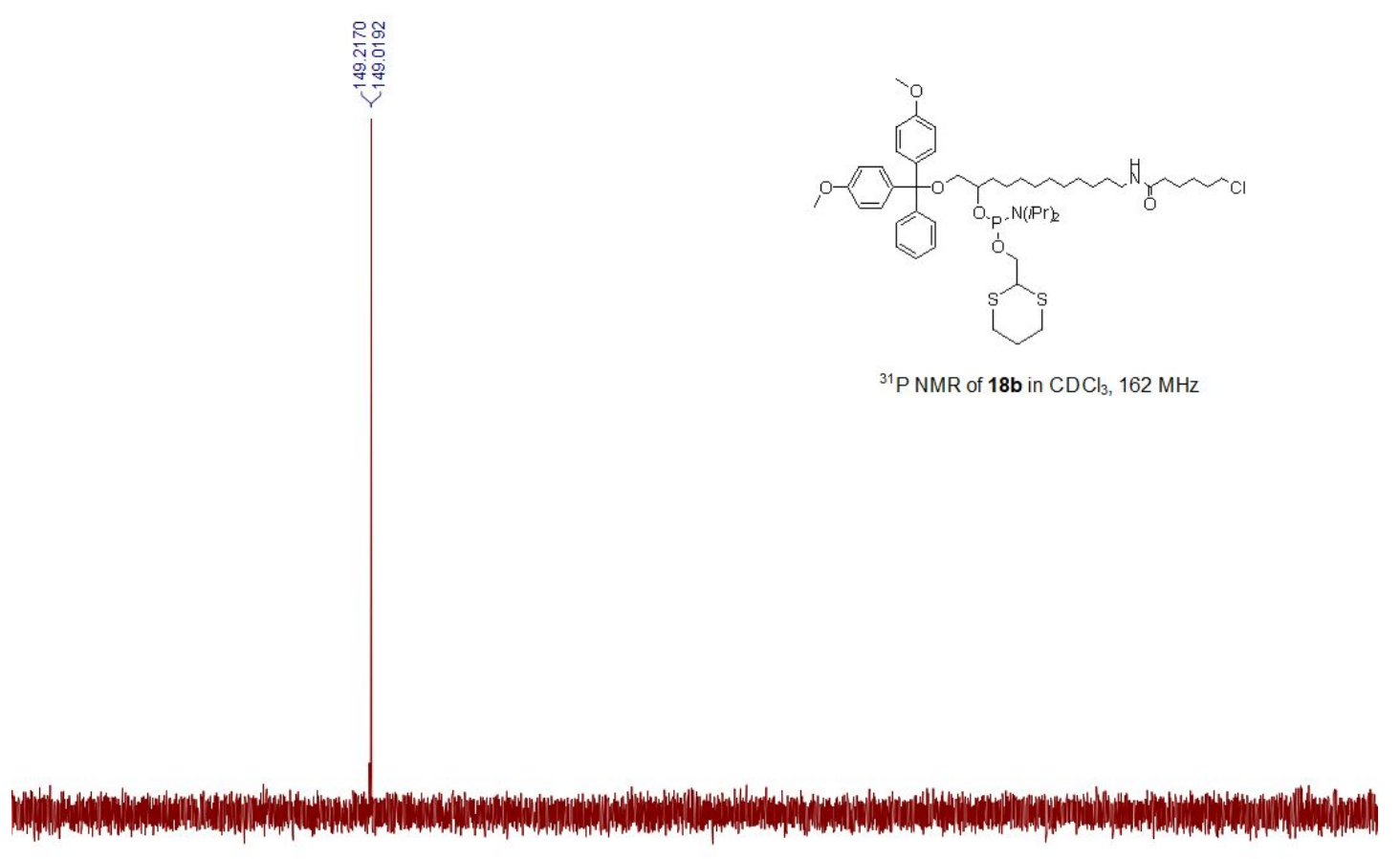

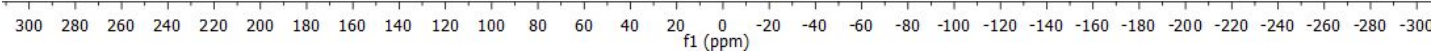

